https://dx.doi.org/10.4314/ijs.v23i1.16

Ife Journal of Science vol. 23, no. 1 (2021)

\title{
POTENTIAL MEDICINAL PLANT REMEDIES AND THEIR POSSIBLE MECHANISMS AGAINST COVID-19: A REVIEW
}

\author{
Ugwah-Oguejiofor, C. J., Adebisi,* I. M. \\ Department of Pharmacology and Toxicology, Faculty of Pharmaceutical Sciences, \\ Usmanu Danfodiyo University, Sokoto, Nigeria \\ *Corresponding Author; E-mail: alaniyab@yahoo.com \\ Received: December 29, 2020; Accepted: March 26, 2021
}

\section{ABSTRACT}

\begin{abstract}
Severe acute respiratory syndrome coronavirus-2 (SARS-CoV-2) outbreak was first reported in Wuhan, a city in Hubei Province of China in December, 2019 and is known to be responsible for the novel coronavirus disease (COVID-19). COVID-19 was declared a pandemic in March, 2020 and since then, it has caused a number of deaths in over 200 countries around the world. Extensive researches have continued in the search of effective vaccines or drug compounds against SARS-CoV-2 and a total of 64 vaccines are currently in clinical trials with 12 currently approved for use by different regulatory bodies, depending on the country. Since the outbreak of SARS-CoV-2, many countries have utilised traditional herbal medicines alongside conventional drugs for the treatment of infected patients. In this review, traditional medicines used to prevent or treat SARS-CoV-2 infection are listed along with the plant parts as used by the traditional healers. Additionally, the possible mechanisms responsible for this preventive or therapeutic outcome are also identified and listed. Our literature search was conducted using Google Scholar, PubMed, Scopus and WHO website. Unpublished reports such as dissertations and theses are not included. Plant parts including roots, leaves, flowers, seeds and so on have been used in the treatment of COVID-19. These traditional medicinal herbs may exert their anti-COVID-19 activity by direct inhibition of the virus replication or entry. Some may act by blocking the ACE-2 receptor, SARS-CoV helicase, Type II Transmembrane Serine Protease (TMPRSS2) and RNA-dependent RNA polymerase (RdRp) activities which are required by SARS-CoV-2 in order to infect human cells. Others act by inhibiting the SARSCoV-2 life-cycle related proteins, namely chymotrypsin-like cysteine protease (3CL-pro) and Papain-like protease (PL-pro). Medicinal plants are promising alternative medicines for the treatment or prevention of SARS-CoV-2 infection. Further researches, are needed to decipher their active components and structures which may suggest clues for the development of drugs against this novel coronavirus.
\end{abstract}

Keywords: Severe Acute Respiratory Syndrome (SARS-CoV-2), COVID-19, medicinal plants, plant parts, mechanism of action, pandemic, 3-chymotrypsin-like cysteine protease

\section{INTRODUCTION}

The novel coronavirus disease (COVID-19) caused by Severe Acute Respiratory Syndrome Coronavirus-2 (SARS-CoV-2) was first reported in Wuhan, a city in Hubei Province of China in December, 2019. The World Health Organization (WHO) declared COVID -19 outbreak a pandemic on March $11^{\text {th }} 2020$ and has since been an enormous challenge for the global public health systems, having affected about two hundred and thirteen (213) countries and territories in the world (WHO, 2020). This viral infection is considered the first pandemic due to a coronavirus (Boukhatem and Setzer, 2020). The WHO report as at $21^{\text {st }}$ March, 2021 shows a cumulative total of one hundred and twenty two million five hundred and twenty four thousand four hundred and twenty four $(122,524,424)$ confirmed cases; Two million seven hundred and three thousand six hundred and twenty
$(2,703,620)$ confirmed deaths globally since the start of the outbreak (WHO, 2021'). Extensive researches have continued in the search of effective vaccines or drug compounds against SARS-CoV-2 and a total of 64 vaccines are currently in clinical trials and 12 are currently approved for use by different regulatory bodies, depending on the country; with those developed by Pfizer (BioNtech), Moderna (mRNA-1273) and Johnson\&Johnson/Janssen (Ad26-COV2,S) approved for use in the United States (WHO, $2021^{\text {b }}$; CDC, 2021). A lot of current research have also focused on repurposed drugs such as antivirals, antimalarials, anti-inflammatory and immune modulators while some potential therapies act in different ways or through multiple mechanisms (Robinson, 2020). The United States Food and Drug Agency, US-FDA recently created a new emergency program; Coronavirus Treatment Acceleration Program (CTAP) aimed 
at speeding up research for the development of COVID-19 treatment (FDA, 2020).

Medicinal plants have been used against SARSCoV-2. This is majorly inspired by the success reported in the treatment of severe acute respiratory syndrome (SARS) caused by the outbreak of SARS coronavirus (SARS-CoV) between 2002 and 2003. There were compelling evidences supporting the beneficial effect in the use of numerous herbal formulas, especially in China and in the Middle East (Chen and Nakamura, 2004; Lau et al., 2005; Hsu et al., 2006). In 2003 for instance, the fatality rate at the outbreak of at SARS-CoV was more than $52 \%$ in Beijing and about 18\% in Singapore and Hong Kong. However in Beijing, this reduced dramatically to $1 \%-4 \%$ just after 10 days, which was believed to be as a result of using plant-based traditional Chinese medicines as a supplement medication with conventional therapy (Chen and Nakamura, 2004). The major druggable targets of SARS-CoV-2 include 3-chymotrypsin- like protease (3CLpro), papain like protease (PLpro), RNA-dependent RNA polymerase (RdRp), angiotensin-converting enzyme 2 (ACE2), SARSCoV helicase and Type II Transmembrane Serine Protease (TMPRSS2) (Wu et al., 2020). Other mechanisms have also been postulated for some medicinal plants such as Immunomodulatory activities. Immunomodulatory agents are compounds that are non-specific and exert their activities without antigenic specificity. These compounds are similar to the adjuvants that are related to some vaccines (Liu et al., 2020). Some medicinal plants with possible immunomodulatory activities have been utilised in traditional medicine for the treatment/prevention of coronavirus. The aim of this review therefore is to document the medicinal herbs that have been reported to be effective against SARS-CoV-2 and their proposed mechanism(s) of action.

\section{Structure and Pathogenesis of SARS-CoV-2} Coronaviruses belonging to the family Coronaviridae, subfamily Coronavirinae are large non- segmented positive-sense single-stranded ribonucleic acid (RNA) viruses with a viral RNA genome of diameter of $80-120 \mathrm{~nm}$ and ranging between 26-32 kb in length. At this length, the coronavirus genome is the largest among RNA viruses (Mittal et al., 2020; Wu et al., 2020). (Fig. 1). They are subdivided into four genera, namely: Alphacoronavirus, Betacoronavirus, Gammacoronavirus, and Deltacoronavirus. Presently all identified coronaviruses that are capable of infecting humans belong to the first two genera (Chu et al., 2020). SARS-CoV-2 is a Betacoronavirus and belongs to the subgenus Sarbecovirus and mostly bear resemblance to a bat coronavirus, with which it shares about $96.2 \%$ sequence homology (Chan et al., 2020). In addition to SARS-CoV-2, the Betacoronavirus genus has two other highly pathogenic coronavirus, namely; the Severe Acute Respiratory Syndrome Coronavirus (SARS-CoV) and the Middle East Respiratory Syndrome Coronavirus (MERS-CoV). SARS-CoV and MERS-CoV infections result in higher mortality rates compared to SARS-CoV-2, but only SARS-CoV-2 is capable of establishing sustained human-to human-transmission (da Silva et al., 2020; Mittal et al., 2020).

The coronavirus genome encodes several structural and non-structural proteins. The structural proteins which are responsible for host infection, membrane fusion, viral assembly, morphogenesis, and release of virus particles, among other functions include Spike (S) protein, envelope $(\mathrm{E})$ protein, membrane $(\mathrm{M})$ protein, and nucleocapsid $(\mathrm{N})$ protein while the non-structural proteins (Nsp) which are not incorporated within the virion particles facilitate viral replication and transcription and are expressed as two huge polyproteins that are then cleaved into 16 smaller proteins (Nsp1-16). This group of proteins include the main protease (Nsp5) and RNA polymerase (Nsp12) (Yoshimoto, 2020). Among the four structural proteins, the $\mathrm{N}$ and $\mathrm{S}$ are the most important. The former helps the virus to develop the capsid and the entire viral structure appropriately and the later helps in the attachment of virus to the host cells (Walls et al., 2020).

Coronaviruses (corona $=$ crown) actually got their name from the crown-shaped appearance of the virus which is as a result of the large Spike (S) glycoprotein, which forms extended homotrimers. It is this spike protein that binds to the animal host cell by interacting with specific anchoring proteins, typically proteinases, such as angiotensin-converting enzyme 2 (ACE-2) or 
aminopeptidase N. This binding of the spike (S) protein facilitates viral entry into the host cell and the release of the viral genome. Current reports have shown that the SARS CoV and SARS-CoV-2 have similar kind of receptors, particularly the receptor binding domain (RBD) and the receptor binding motif (RBM) present in the viral genome (Yin and Wunderink, 2018). In the course of the SARS infection, the RBM of the $\mathrm{S}$ protein gets directly attached to ACE-2 in the host cells. Since ACE-2 protein is expressed in various organs of the human body chiefly in the lungs, kidney and intestine, these organs become the prime targets of the coronavirus (Zhao etal., 2020).

Following the attachment, the host protease usually influences the cleaving of the receptor attached spike protein and the fusion of virus into host cell. Based on the protease type, SARS coronaviruses follow two different paths to penetrate into the host cell. Firstly, a SARS virus may enter into the cell through endocytosis at the presence of host's $\mathrm{pH}$-dependent cysteine protease cathepsin $\mathrm{L}$, which leads to formation of a membrane bounded endosome (Figure 2A). This protease induces the activation of the attached spike protein which leads to changes in shape of endosome and helps the viral envelope to fuse with the endosomal wall (Simmons et al., 2013). Secondly, the presence of type II transmembrane serine protease (TMPRSS2) at the outer membrane of some epithelial tissues such as respiratory, urogenital and gastrointestinal induces proteolytic cleavage of viral spike protein. The S2'site of the $S$ protein comprises single lysine or arginine residues which can be targeted by TMPRSS2 for cleaving, hence SARS and other respiratory viruses can penetrate into the host cell directly by a fusion of viral envelope and host cell membrane (Figure 2B) (Heurich et al., 2014). When the fusion is completed, the virus releases its nucleocapsid into the cytoplasm where the viral genome mimics the messenger RNA and takes part in the translation process by cell ribosome (Figure 2A). The mRNAs further translates accessory proteins and structural proteins. The structural proteins (envelope glycoproteins), nucleocapsid proteins and newly synthesized genomic RNA reorganize to form progeny viruses. Finally, the virion containing viral particles discharge from the infected cell through secretory vesicles by exocytose process (Figure 2A), (Zhang et al., 2020).

\section{Symptoms and Risk of COVID-19 Infection}

The current coronavirus disease affects different people in different ways, the presentation ranging from asymptomatic/mild symptoms to severe illness and death (Esakandari et al., 2020). Most common symptoms include fever, dry cough, and tiredness while the less common symptoms include aches and pains, sore throat, diarrhea, conjunctivitis, headache, loss of taste or smell, a rash on skin, or discolouration of fingers or toes. Serious symptoms are difficulty in breathing or shortness of breath, chest pain or pressure and loss of speech or movement (WHO, 2020'). At the early stage of the pandemic, an analysis of some patients showed that $17.6 \%$ were severe cases while $82.4 \%$ were common cases, which include $73.3 \%$ mild cases, $4.2 \%$ non-pneumonia cases and $5.0 \%$ asymptomatic cases respectively (Tian $e t$ al., 2020). The most common symptoms at the onset of illness were fever $(82.1 \%)$, cough $(45.8 \%)$, fatigue $(26.3 \%)$, dyspnea $(6.9 \%)$ and headache $(6.5 \%)$ with a reported fatality of $0.9 \%$ (Tian $e t a l$., 2020). In another systematic review and meta analysis, Jain and Yuan (2020) found that cough, fever and fatigue were the most prevalent symptoms in the severe disease while cough, fever and dyspnoes were the symptoms that warranted intensive care unit admission. Older population have a higher risk of serious illness from COVID19 , and this risk is known to increase with age $\left(C D C, 2020^{2}\right)$. Another factor that may increase risk of serious illness include pre- existing chronic medical conditions such as heart diseases, cancer, diabetes, severe obesity, chronic kidney disease, sickle cell disease, weakened immune system from solid organ transplants, HIV or some medications and high blood pressure (CDC, 2020 $)$.

\section{Current conventional treatment and the Role of Traditional Medicine in the search for agents against SARS-CoV-2}

Quite a number of conventional/ Orthodox medicine treatment are under investigations and at different phases of clinical trials; Remdesivir, was given an emergency use authorization (EUA) on $1^{\text {st }}$ May, 2020, being the drug that has gone furthest along in clinical trials (FDA, 2020 $)$. Other drugs 
that are being used include corticosteroids such as Dexamethasone (Horby et al., 2020), Tocilizumab (Samaee et al., 2020; Potere et al., 2020), Hydroxychloroquine and Chloroquine (Gao et al., 2020), Azithromycin (Bleyzac et al., 2020), Lopinavir/Ritonavir (Lu, 2020), Abidol (Lu, 2020) Oseltamivir (Chiba, 2020), Favipiravir (De Clercq, 2019), Colchicine (Schlesinger et al., 2020, Ivermectin (Chaccour et al, 2020) and Convalescent plasma (FDA, 2020). There are thousands of clinical trials of COVID-19 therapies taking place across the world. Updated list of these numerous trials are available at World Health Organization's International Clinical Trials Registry Platform (WHO ICTRP, 2020) and at ClinicalTrials.gov (2020).

The use of traditional medicine for the treatment of various ailments/ diseases is dated back to 4000-5000 BC (Hosseinzadeh et al., 2015). The WHO in recognition of the important role of traditional medicine, developed a strategy in response to the World Health Assembly resolution on traditional medicine (WHA62.13) aimed at supporting member states in developing proactive policies and implementing action plans that will strengthen the role traditional medicine plays in keeping the population healthy (WHO, 2013). Since the prehistoric times, people from different parts of the world have been utilizing medicinal plants to mitigate against infectious diseases (Andrighetti-Frohner et al., 2005; Yang et al., 2020). For instance, Indian herbs have been used as a treatment and preventive strategy for several diseases, including respiratory viral infections (Vellingiri, 2020), Traditional Chinese Medicine (TCM) has played an essential role in treating epidemic diseases in the long history of China. Also, At least eighty per cent $(80 \%)$ of African populations use some form of traditional herbal medicine (Willcox and Bodeker, 2004)'The WHO has estimated that the worldwide annual market for medicinal plant product approaches US\$ 60 billion (Linde and Jonas, 1999). The popularity of traditional medicine has been attributed to some of its advantages such as affordability, availability, acceptability, and apparently low toxicity compared to orthodox medicine (Sofowora, 1993).

Medicinal plants contain diverse secondary metabolites, some of which are believed to have the ability to interfere with viral protein and enzyme activities hence prevent viral entry/penetration into the host cells and replication within it ( $\mathrm{Li}$ and Peng, 2013). The efficacies of some of these plant-based therapies were confirmed in combating SARS in 2003 (Zhang, et al, 2004). With many similarities being found between SARS-CoV and SARS-CoV-2 (e.g both of them belonging to the same beta family and containing the same genetic material i.e. RNA; both attaching to the host cell through same ACE2 receptor and with an eighty-six percent $(86 \%)$ identity and ninety-six percent $(96 \%)$ similarity of genome); previously employed plant metabolites for SARS-CoV in 2003 can be considered as emerging drug candidates for COVID-19 (Bhuiyan et al., 2020).

At the early stage of the COVID-19 pandemic in China, the treatment protocol of COVID-19 highlights the combination of TCM with conventional/Western therapy. Yang et al. (2020) reported that greater than $85 \%$ of SARS-CoV-2 infected patients in China were receiving TCM treatment. This practice has demonstrated that TCM intervention is effective in the management of COVID-19. This is evident in the improvement of the cure rate, shortened course of the disease/delayed disease progression and a reduction in mortality rate (Chan et al., $2020^{\mathrm{b}}$, Luo et al., 2020ª Luo et al, 2020 b , Ren et al., 2020, Wan et al., 2020).

Table 1 consist of a list of medicinal plants that has been reportedly used in the prevention and treatment of COVID-19 in different parts of the world. 
Table 1: Medicinal plants with activity against SARS-CoV-2

\begin{tabular}{|c|c|c|c|c|c|}
\hline $\mathrm{S} / \mathrm{N}$ & Botanical name & Family & $\begin{array}{l}\text { Common name/ } \\
\text { Local name }\end{array}$ & Part used & Reference \\
\hline 1 & Saxifraga spinulosa & Saxifragaceae & $\begin{array}{l}\text { Spider plant/spider } \\
\text {-legged saxifrage }\end{array}$ & Aerial parts & Takeda et al., 2020 \\
\hline 2 & Strobilanthes callosa & Acanthaceae & Karvi & Leaf & \multirow{6}{*}{ Luo et al, 2020c } \\
\hline 3 & Strobilanthes cusia & Acanthaceae & Assam Indigo & Leaf & \\
\hline 4 & $\begin{array}{l}\text { Astragalus } \\
\text { membranaceus }\end{array}$ & Fabaceae & $\begin{array}{l}\text { Mongolian } \\
\text { milkvetch }\end{array}$ & Root & \\
\hline 5 & Glycyrrhiza glabra) & Fabaceae & Liquorice & Root & \\
\hline 6 & Saposhnikovia divaricate & Apiaceae & fang feng Siler & Root & \\
\hline 7 & Atractylodes lancea & Asteraceae & Cang Zhu. & Rhizome & \\
\hline 8 & Lonicera japonica & Caprifoliaceae & $\begin{array}{l}\text { Japanese } \\
\text { honeysuckle }\end{array}$ & $\begin{array}{l}\text { Leaves and } \\
\text { Flowers }\end{array}$ & \multirow[t]{2}{*}{ Yang et al., 2020} \\
\hline 9 & Forsythia suspensa & Oleaceae & Golden Bell & Fruit & \\
\hline 10 & Capsicum annuиm & Solanaceae & $\begin{array}{l}\text { Sweet Pepper } \\
\text { Cayenne Pepper, } \\
\text { Chili Pepper }\end{array}$ & Seed & \multirow{3}{*}{$\begin{array}{l}\text { Khaerunnisa et al., } \\
2020\end{array}$} \\
\hline 11 & Mentha & Lamiaceae & Horse mint & $\begin{array}{l}\text { Aerial part } \\
\text { (Stem and } \\
\text { leaf) }\end{array}$ & \\
\hline 12 & $\begin{array}{l}\text { Olea } \\
\text { europaea }\end{array}$ & Oleaceae & Olive & Leaf & \\
\hline 13 & Lindera aggregate & Lauraceae & Spicewood & Root & \multirow{3}{*}{$\begin{array}{l}\text { Suryanarayana and } \\
\text { Banavath, } 2020\end{array}$} \\
\hline 14 & Pynosia lingua & Polypodiaceae & Tongue Fern & Rhizome & \\
\hline 15 & Lycoris radiate & Amaryllidaceae & Red spider lily & Bulb & \\
\hline 16 & Stephania tetrandra & Menispermaceae & $\begin{array}{l}\text { Stephanial } \\
\text { Fen Fang Ji }\end{array}$ & Root & Kim et al., 2014 \\
\hline 17 & Clivia miniata & Amaryllidaceae & Natal lily or bush lily & Rhizome & \multirow[b]{2}{*}{ Shen et al., 2019} \\
\hline 18 & Carapichea ipecacuanha & Rubiaceae & Ipecac. & Root & \\
\hline 19 & Broussonetia papyrifera & Moraceae. & Paper mulberry & Root & Park et al., 2017 \\
\hline 20 & $\begin{array}{l}\text { Citrus } \\
\text { sinensis }\end{array}$ & Rutaceae & Sweet orange & $\begin{array}{l}\text { Peel } \\
\text { (Pericarp) }\end{array}$ & \multirow[t]{3}{*}{ Ulasli et al., 2014} \\
\hline 21 & $\begin{array}{l}\text { Nigella } \\
\text { Sativa }\end{array}$ & Ranunculaceae & $\begin{array}{l}\text { Black cumin, Black } \\
\text { seed, Black caraway }\end{array}$ & Seed & \\
\hline 22 & $\begin{array}{l}\text { Anthemis } \\
\text { Hyaline }\end{array}$ & Asteraceae & Chamomile & $\begin{array}{l}\text { Flower and } \\
\text { buds }\end{array}$ & \\
\hline 23 & Paulownia tomentosa & Paulowniaceae & $\begin{array}{l}\text { Paulownia, empress } \\
\text { tree or Princess tree }\end{array}$ & Fruit & Cho et al., 2013 \\
\hline 24 & Pelargonium sidoides & Geraniaceae & $\begin{array}{l}\text { African geranium } \\
\text { and South African } \\
\text { geranium. }\end{array}$ & NA & $\begin{array}{l}\text { Michaelis et al., } \\
2011\end{array}$ \\
\hline 25 & Cibotium barometz. & Dicksoniaceae & $\begin{array}{l}\text { Chain Fern_Golden } \\
\text { Hair Dog Fern, } \\
\text { Golden Moss }\end{array}$ & Rhizome & \multirow{4}{*}{ Wen et al., 2011} \\
\hline 26 & Gentiana scabra & Gentianaceae & Japanese gentian & Rhizome & \\
\hline 27 & Taxillus chinensis & Loranthaceae & Chinese Mistletoe & Stem and Leaf & \\
\hline 28 & Cassia tora, & Leguminosae & $\begin{array}{l}\text { Sickle Senna, Sickle } \\
\text { pod }\end{array}$ & Seed & \\
\hline 29 & Dioscorea batata, & Dioscoreaceae & Chinese Yam & Tuber & \\
\hline 30 & Torreya nucifera & Taxaceae & $\begin{array}{l}\text { Japanese nutmeg - } \\
\text { yew or Japanese } \\
\text { torreya }\end{array}$ & Leaf & Ryu et al., 2010 \\
\hline 31 & Houttuynia cordata & Saururaceae & $\begin{array}{l}\text { Fish mint, Rainbow } \\
\text { plant, Chameleon } \\
\text { plant }\end{array}$ & NA & Lau et al., 2008 \\
\hline
\end{tabular}




\begin{tabular}{|c|c|c|c|c|c|}
\hline 32 & Rheum officinale & Polygonaceae & Chinese rhubarb & Tuber & \multirow[b]{2}{*}{ Ho et al., 2007} \\
\hline 33 & $\begin{array}{l}\text { Polygonum } \\
\text { multiflorum }\end{array}$ & Polygonaceae & $\begin{array}{l}\text { Tuber fleeceflower, } \\
\text { Chinese knotweed. }\end{array}$ & $\begin{array}{l}\text { Tuber and } \\
\text { Vines }\end{array}$ & \\
\hline 34 & Pogostemon cablin & Lamiaceae & Patchouli & Aerial part & \multirow{9}{*}{ Pan et al., 2020} \\
\hline 35 & Perilla Frutescens & Lamiaceae & $\begin{array}{l}\text { Perilla or Korean } \\
\text { perilla }\end{array}$ & Leaf & \\
\hline 36 & Angelica dahurica & Umbelliferae & Bai Zhi & Root & \\
\hline 37 & $\begin{array}{l}\text { Atractylodes } \\
\text { macrocephala }\end{array}$ & Compositae & $\begin{array}{l}\text { Largehead } \\
\text { atractylode, Bai Zhu }\end{array}$ & Rhizome & \\
\hline 38 & Citrus reticulata & Rutaceae & Mandarin & $\begin{array}{l}\text { Peel } \\
\text { (Pericarp) }\end{array}$ & \\
\hline 39 & Pinellia ternata & Araceae & Crow-dipper & Tuber & \\
\hline 40 & Magnolia officinalis & Magnoliaceae & Houpu magnolia & Bark & \\
\hline 41 & Lonicera Japonica & Caprifoliaceae & Japanese honeysuckle & $\begin{array}{l}\text { Leaf and } \\
\text { Flowers }\end{array}$ & \\
\hline 42 & Fritillaria thunbergii & Liliaceae & Zhe Bei Mu & Bulb & \\
\hline 43 & Scutellariae baicalensis & Lamiaceae & $\begin{array}{l}\text { Baikal skullcap, } \\
\text { Chinese skullcap }\end{array}$ & Root & \\
\hline 44 & Arctium lappa & Asteraceae & Greater burdock & Fruit & \\
\hline 45 & Artemisia annua, & Asteraceae & Sweet wormwood & Leaf & \\
\hline 46 & Forsythia suspensa, & Oleaceae. & Weeping forsythia & Fruit & \\
\hline 47 & Ephedra sinica & Ephedraceae & $\begin{array}{l}\text { Ma huang, Yellow } \\
\text { horse, Sea grape }\end{array}$ & $\begin{array}{l}\text { Stem/ Aerial } \\
\text { part }\end{array}$ & \\
\hline 48 & Prunus armeniaca & Rosaceae & Siberian apricot & Seed & \\
\hline 49 & Isatis indigotica & Brassicaceae & Woad & Root & \\
\hline 50 & Dryopteris crassirbizoma & Dryopteridaceae. & Male fern & Rhizome & \\
\hline 51 & Pogostemon cablin & Lamiaceae & Mint & Aerial part & \\
\hline 52 & Polygonum cuspidatum & Polygonaceae & $\begin{array}{l}\text { Asian knotweed/ } \\
\text { Japanese knotweed. }\end{array}$ & $\begin{array}{l}\text { Rhizome and } \\
\text { root }\end{array}$ & \\
\hline 53 & Bupleurum chinense & $\begin{array}{l}\text { Apiaceae/ } \\
\text { Umbelliferae. }\end{array}$ & Bei Chai Hu. & Root & Pan et al., 2020 \\
\hline 54 & Glycyrrbiza uralensis & Leguminosae & Licorice & $\begin{array}{l}\text { Rhizome and } \\
\text { Root }\end{array}$ & \\
\hline 55 & Schizonepeta tenuifolia & Lamiaceae. & $\begin{array}{l}\text { Japanese mint/ } \\
\text { Japanese catnip }\end{array}$ & Spike & \\
\hline 56 & Menthae haplocalyx & Lamiaceae & $\begin{array}{l}\text { Mentha/ } \\
\text { Peppermint }\end{array}$ & Aerial part & \\
\hline 57 & Carthamus tinctorius & Asteraceae & Safflower & Flower & \\
\hline 58 & Ligusticum chuanxiong & Umbelliferae & - & Rhizome & \\
\hline 59 & Salvia miltiorrbiza & Lamiaceae & $\begin{array}{l}\text { Red sage, Chinese } \\
\text { sage }\end{array}$ & $\begin{array}{l}\text { Rhizome and } \\
\text { Root }\end{array}$ & \\
\hline 60 & Panax ginseng & Araliaceae. & $\begin{array}{l}\text { Asian ginseng, } \\
\text { Chinese ginseng, or } \\
\text { Korean ginsen }\end{array}$ & $\begin{array}{l}\text { Rhizome and } \\
\text { root }\end{array}$ & \\
\hline 61 & Ophiopogon japonicus & Liliaceae & Mondo grass & Root & \\
\hline 62 & Schisandra chinensis & Schisandraceae & Magnolia-vine & Fruit & \\
\hline 63 & Aconitum carmichaelii & Ranunculaceae & $\begin{array}{l}\text { Chinese aconite, } \\
\text { Carmichael's } \\
\text { monkshood or } \\
\text { Chinese wolfsbane }\end{array}$ & Root & \\
\hline 64 & Forsythia suspensa & Oleaceae & Lianqiao & Fruit & \\
\hline 65 & Gardenia jasminoides & Rubiaceae & Cape jasmine & Fruit & Pan et al., 2020 \\
\hline
\end{tabular}


Ugwah-Oguejiofor and Adebisi: Potential Medicinal Plant Remedies and Their Possible Mechanisms

\begin{tabular}{|c|c|c|c|c|c|}
\hline 66 & Trichosanthes kirilowii & Cucurbitaceae & $\begin{array}{l}\text { Chinese snake } \\
\text { gourd, Chinese } \\
\text { cucumber }\end{array}$ & Fruit & \multirow{21}{*}{ Luo et al., $2020^{c}$} \\
\hline 67 & Coptis chinensis & Ranunculaceae & Huang Lian & Rhizome & \\
\hline 68 & Rheum palmatum & Polygonaceae & Rhubarb & $\begin{array}{l}\text { Root and } \\
\text { Rhizome }\end{array}$ & \\
\hline 69 & Lophatherum gracile & Poaceae & Bamboo-leaf & Leaf & \\
\hline 70 & Pogostemon cablin & Lamiaceae & Patchouli & Leaf & \\
\hline 71 & Coix lacryma & Gramineae & Coix seed & Seed & \\
\hline 72 & Amomum compactum & Zingiberaceae & Round cardamom & Fruit & \\
\hline 73 & Medulla Tetrapanacis & Amaranthaceae & $\begin{array}{l}\text { Rice Paper Plant } \\
\text { Pith, Tong Cao }\end{array}$ & Leaf & \\
\hline 74 & Glycine max & Fabaceae & Soybean & Seed & \\
\hline 75 & Alisma orientale & Alismataceae & $\begin{array}{l}\text { Asian water } \\
\text { plantain, }\end{array}$ & Rhizome & \\
\hline 76 & Magnolia officinalis & Magnoliaceae & $\begin{array}{l}\text { Houpu magnolia, } \\
\text { Magnolia-bark }\end{array}$ & Bark & \\
\hline 77 & Cyrtomium fortunei & Dryopteridaceae & Holly fern & Aerial part & \\
\hline 78 & Rhodiola crenulata & Crassulaceae & Stonecrops & $\begin{array}{l}\text { Root and } \\
\text { Rhizome }\end{array}$ & \\
\hline 79 & Aucklandia lappa & Asteraceae & Costus, Mu Xiang & Root & \\
\hline 80 & Aquilaria agallocha & Thymelaeaeeae & $\begin{array}{l}\text { Agarwood, } \\
\text { Aloeswood }\end{array}$ & Rhizome & \\
\hline 81 & Scrophularia ningpoensis & Scrophulariaceae & $\begin{array}{l}\text { Ningpo figwort or } \\
\text { Chinese figwort, } \\
\text { Xuanshen }\end{array}$ & Root & \\
\hline 82 & Cimicifuga racemosa & Ranunculaceae & Black Cohosh & Rhizome & \\
\hline 83 & Sysygium aromaticum & Myrtaceae & Clove & Flower buds & \\
\hline 84 & Lanxangia tsaoko & Zingiberaceae & $\begin{array}{l}\text { Cardamom } \\
\text { Tsao-ko }\end{array}$ & Fruits & \\
\hline 85 & $\begin{array}{l}\text { Anemarrhena } \\
\text { asphodeloides }\end{array}$ & Asparagaceae & Zhi Mu & Rhizome & \\
\hline 86 & Paeonia lactiflora & Paeoniaceae & Chinese peony & Root & \\
\hline 87 & Bupleurum falcatum & Apiaceae & $\begin{array}{l}\text { Sickle-leaved hare's- } \\
\text { ear, Chinese } \\
\text { Thoroughwax, } \\
\text { Sickle hare's ear }\end{array}$ & Root & \\
\hline 88 & Ziziphus jujuba & Rhamnaceae & $\begin{array}{l}\text { Chinese date tree, } \\
\text { Common jujube }\end{array}$ & Fruit & \multirow{6}{*}{ Luo et al., 2020c } \\
\hline 89 & Descurainia sophia & Brassicaceae & Flixweed & Seed & \\
\hline 90 & Fritillaria thunbergii & Liliaceae & Zhe Bei Mu & Bulb & \\
\hline 91 & Cimicifuga heracleifolia & Ranunculaceae & Black Cohosh & Rhizome & \\
\hline 92 & Notopterygium incisum & Apiaceae & Qiang Huo. & $\begin{array}{l}\text { Rhizome and } \\
\text { Root }\end{array}$ & \\
\hline 93 & Curcuma longa & Zingiberaceae & Turmeric & $\begin{array}{l}\text { Rhizome and } \\
\text { Root }\end{array}$ & \\
\hline 94 & Withania somnifera & Solanaceae & $\begin{array}{l}\text { Ashwagandha, } \\
\text { Indian ginseng, } \\
\text { Poison gooseberry } \\
\text { or Winter cherry }\end{array}$ & Root & \\
\hline 95 & Tinospora cordifolia & Menispermaceae & Guduchi & Root & \\
\hline 96 & Ocimum sanctum & Lamiaceae & Holy basil, Tulsi & Leaf & \\
\hline 97 & Leptadenia reticulata & Apocynaceae & Dori & $\begin{array}{l}\text { Root, Aerial } \\
\text { parts }\end{array}$ & \\
\hline 98 & Pavonia odorata & Malvaceae & $\begin{array}{l}\text { Fragrant Sticky } \\
\text { Mallow. }\end{array}$ & Root & \\
\hline
\end{tabular}




\begin{tabular}{|c|c|c|c|c|c|}
\hline 99 & Cedrus deodara & Pinaceae & Deodar Cedar & Heart wood & \multirow{11}{*}{$\begin{array}{l}\text { Balkrishna et al., } \\
2020\end{array}$} \\
\hline 100 & Cyperus scariosus, & Cyperaceae & Cypriol, Nutgrass & Root & \\
\hline 101 & Cinnamomum verum & Lauraceae & $\begin{array}{l}\text { True cinnamon tree } \\
\text { or Ceylon cinnamon } \\
\text { tree }\end{array}$ & Bark & \\
\hline 102 & Chrysopogon rizanioides & Poaceae & Vetiver, & Whole plant & \\
\hline 103 & Hemidesmus indicus & Apocynaceae & Indian sarsaparilla & Root & \\
\hline 104 & Santalum album & Santalaceae & Indian sandalwood & Heartwood & \\
\hline 105 & Berberis aristata & Berberidaceae & $\begin{array}{l}\text { Indian barberry, } \\
\text { "chutro" or Tree } \\
\text { turmeric }\end{array}$ & Root bark & \\
\hline 106 & Aquilaria agallocha & Thymelaeaceae & $\begin{array}{l}\text { Agarwood, } \\
\text { Aloeswood }\end{array}$ & Root & \\
\hline 107 & Solanum indicum & Solanaceae & $\begin{array}{l}\text { Indian Night Shade, } \\
\text { Poison Berry }\end{array}$ & Root, Fruit & \\
\hline 108 & Pluchea lanceolata & Asteraceae & Indian fleabane & Leaf & \\
\hline 109 & Nelumbo nucifera & Nelumbonaceae & Sacred lotus & $\begin{array}{l}\text { Rhizomes, } \\
\text { Leaves and } \\
\text { Seed }\end{array}$ & \\
\hline 110 & Pistacia integerrima & Anacardiaceae & Zebrawood & Gall & \multirow{4}{*}{ Balkrishna, 2020} \\
\hline 111 & Cressa cretica & Convolvulaceae & Salt Cresse & Fruit & \\
\hline 112 & Piper nigrum & Piperaceae & Black pepper & Fruit & \\
\hline 113 & Anacyclus pyrethrum & Asteraceae & Spanish chamomile & Root & \\
\hline 114 & Embelia ribes & Myrsinaceae & False black pepper & Fruit & \multirow[t]{5}{*}{ Rastogi et al., 2020} \\
\hline 115 & Terminalia chebula & Combretaceae & $\begin{array}{l}\text { Black- or chebulic } \\
\text { myrobalan }\end{array}$ & Fruit & \\
\hline 116 & Emblica officinalis & Euphorbiaceae & Indian gooseberry & Fruit & \\
\hline 117 & $\begin{array}{l}\text { Acorus } \\
\text { calamus }\end{array}$ & Acoraceae & $\begin{array}{l}\text { Sweet flag or } \\
\text { Calamus }\end{array}$ & Root & \\
\hline 118 & $\begin{array}{l}\text { Aconitum } \\
\text { beterophyllum }\end{array}$ & Ranunculaceae & $\begin{array}{l}\text { Aconite, } \\
\text { Monkshood, Wolf's- } \\
\text { bane, Leopard's } \\
\text { bane }\end{array}$ & Root & \\
\hline 119 & Cynanchi Stauntonii & Asclepiadaceae & $\begin{array}{l}\text { Cynanchum Root } \\
\text { and Rhizome Prime } \\
\text { White Root }\end{array}$ & $\begin{array}{l}\text { Rhizome and } \\
\text { Root }\end{array}$ & \multirow[t]{2}{*}{ Ang et al., 2020} \\
\hline 120 & Fritillariae Thunbergii & Liliaceae & Zhe bei mu & Bulb & \\
\hline
\end{tabular}

$*$ NA $=$ Not available 


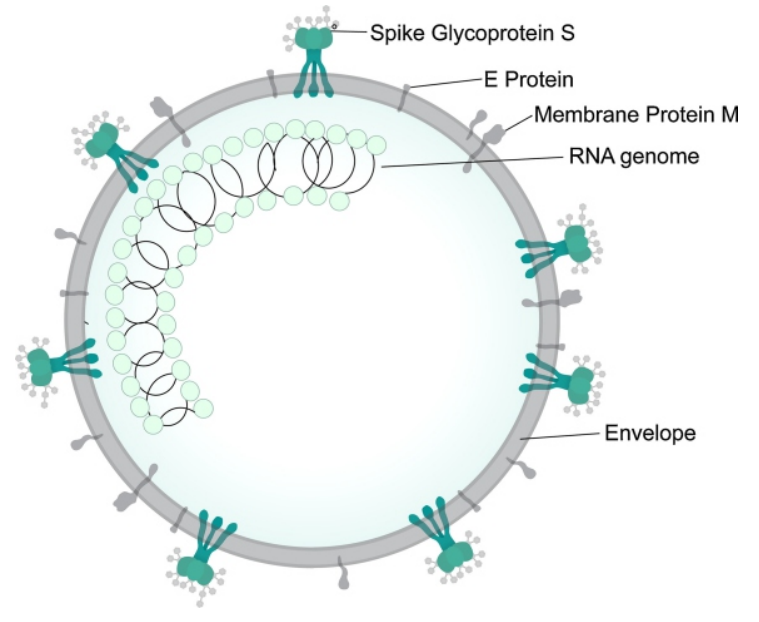

Figure 1: The general structure of a SARS-CoV-2 (reproduced from Wikipedia under CC licence 4.0). E protein $=$ envelope protein (Mani et al., 2020)
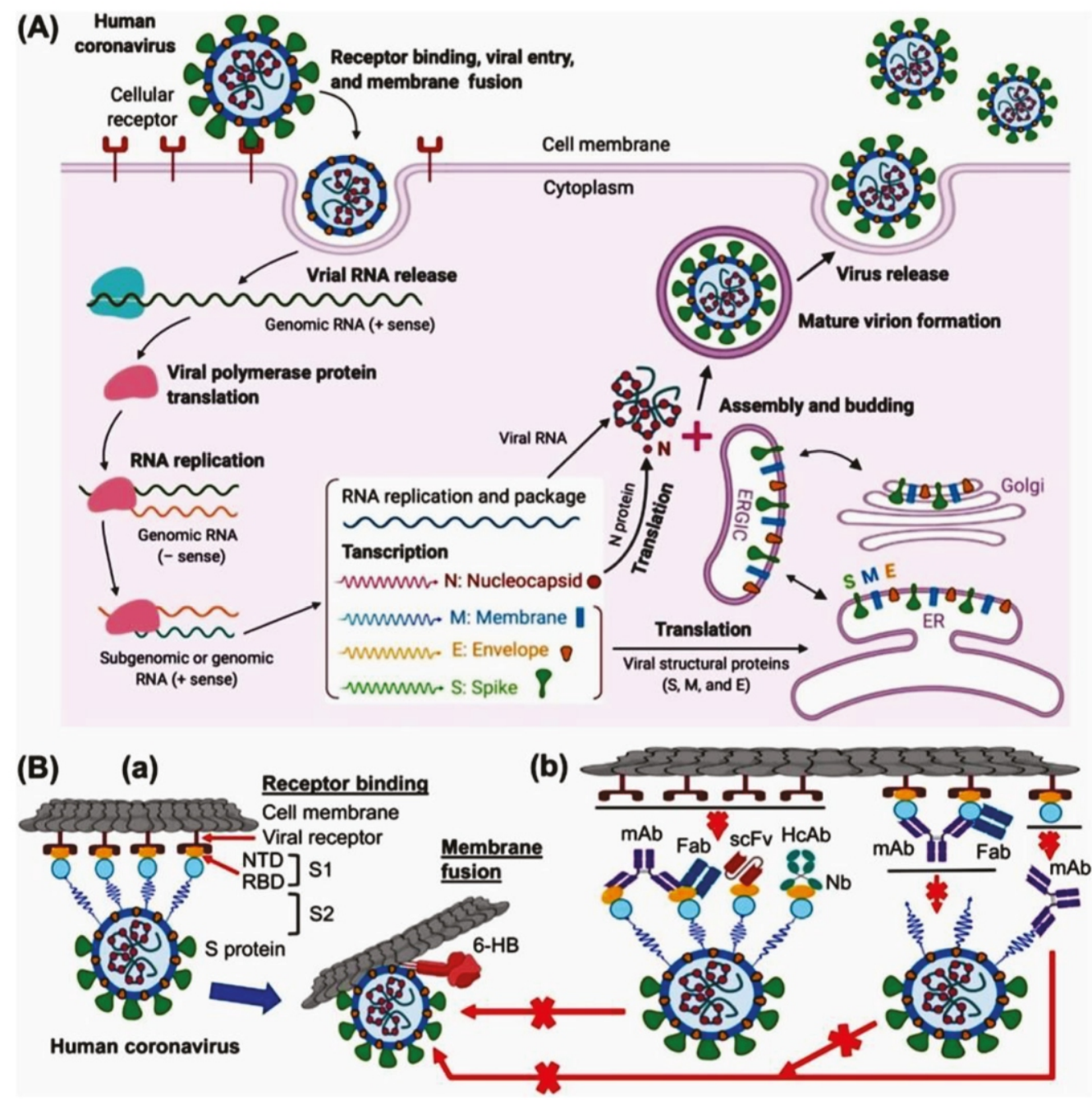

Figure 2. (A) Replication cycle of human coronavirus; (B) host cell receptor and viral protein (S-protein) binding and membrane fusion mechanism (Jiang et al., 2020). 
Potential mechanism of action of plants used against SARS-CoV-2

Medicinal plants with potential activity against 3chymotrypsin-like cysteine protease (SARS-CoV 3CLpro) abound (Upadhyay et al., 2020; ul Qamar et al., 2020; Benarba and Pandiella, 2020) (Table 2). 3-Chymotrypsin-like protease is necessary for viral replication and as such an important drug target for SARS-CoV-2 therapeutic agents. Other potential mechanisms through which medicinal plants act which are also important targets for therapeutic agents include angiotensin-converting enzyme 2 (ACE2) (Table 3), SARS-CoV- PLpro activity (Table 4), SARS-CoV helicase (Table 5), Type II Transmembrane Serine Protease (TMPRSS2) (Table 6), RNA-dependent RNA polymerase (RdRp) (Table 7) and Immunomodulatory activities (Table 8).

Table 2: Medicinal plants with potential activity against 3-chymotrypsin-like cysteine protease (SARSCoV 3CLpro) of SARS-CoV-2

\begin{tabular}{|c|c|c|c|c|}
\hline $\mathrm{S} / \mathrm{N}$ & Medicinal plant & Family & Other Pharmacologic action & References \\
\hline 1. & Psorothamnus arborescens & Fabaceae & Anti-SARS-CoV-2 activity & Idrees et al., 2020 \\
\hline 2. & Myrica cerifera & Myricaceae & $\begin{array}{l}\text { Anti-cancer and Antioxidant } \\
\text { activities }\end{array}$ & $\begin{array}{l}\text { Paul et al., } 2013 \\
\text { Zhang et al., } 2016\end{array}$ \\
\hline 3. & Cassine xylocarpa & Celastraceae & Anti-HIV activity & Osorio et al., 2011 \\
\hline 4. & Phyllanthus emblica ${ }^{a}$ & Phyllanthaceae & $\begin{array}{l}\text { Antimicrobial and Anti } \\
\text { inflammatory activities }\end{array}$ & $\begin{array}{l}\text { Gaire and Subedi, 2014; } \\
\text { Asmilia et al., } 2020\end{array}$ \\
\hline 5. & Tinospora cordifolief & Menispermaceae & $\begin{array}{l}\text { Immunomodulatory activity; } \\
\text { Anti-HIV }\end{array}$ & $\begin{array}{l}\text { Kalikar et al ., 2008; } \\
\text { Akhtar, } 2010\end{array}$ \\
\hline 6. & Commiphora wightii & Burseraceae & Anti-cancer activity & Uzma et al., 2020 \\
\hline 7. & Curcuma longa & Zingiberaceae & $\begin{array}{l}\text { Anti-allergic and Anti -cancer } \\
\text { activities }\end{array}$ & $\begin{array}{l}\text { Choi et al., 2010; Kuttan } \\
\text { et al., } 1985\end{array}$ \\
\hline 8. & Terminali chebula & Combretaceae & $\begin{array}{l}\text { Anti-HSV-2 and Antitussive } \\
\text { activities }\end{array}$ & $\begin{array}{l}\text { Kesharwani et al., 2017; } \\
\text { ul Haq et al., 2013 }\end{array}$ \\
\hline 9. & Glycyrrbiza glabra, & Fabaceae & $\begin{array}{l}\text { Antitussive, Expectorant and } \\
\text { Antiviral activities }\end{array}$ & $\begin{array}{l}\text { Kamei et al., 2003; De } \\
\text { Clercq, 2000; } \\
\text { Lalita,1994 }\end{array}$ \\
\hline 10. & Azadirachta indica & Meliaceae & $\begin{array}{l}\text { Antimalarial and Antiviral } \\
\text { activities }\end{array}$ & $\begin{array}{l}\text { Deshpande et al., 2014; } \\
\text { Badam et al., } 1999\end{array}$ \\
\hline 11. & Boswellia serrate & Burseraceae & $\begin{array}{l}\text { Immunomodulatory and Anti - } \\
\text { inflammatory activities }\end{array}$ & $\begin{array}{l}\text { Beghelli et al., 2017; } \\
\text { Siddiqui, 2011 }\end{array}$ \\
\hline 12. & Zingiber officinale & Zingiberaceae & $\begin{array}{l}\text { Antiviral, Immunomodulatory } \\
\text { and Anti } \\
\text { activities }\end{array}$ & $\begin{array}{l}\text { San et al., 2013; Carrasco } \\
\text { et al., 2009; Ezzat et al., } \\
2018\end{array}$ \\
\hline 13. & Helianthus annuus & Asteraceae & $\begin{array}{l}\text { Anti-asthmatic and Antiviral } \\
\text { activities }\end{array}$ & $\begin{array}{l}\text { Heo et al., 2008; Oliveira } \\
\text { et al., } 2009\end{array}$ \\
\hline 14. & Ocimum sanctum & Lamiaceae & $\begin{array}{l}\text { Immunomodulatory, Antiviral } \\
\text { and Anti-asthmatic activities }\end{array}$ & $\begin{array}{l}\text { Jeba and Rameshkumar, } \\
\text { 2011; Ghoke et al., } \\
\text { 2018; Vinaya, } 2017\end{array}$ \\
\hline 15. & Hyptis atrorubens Poit & Lamiaceae & Antimicrobial activity & $\begin{array}{l}\text { Kerdudo et al ., 2016; } \\
\text { Abedini et al., } 2013\end{array}$ \\
\hline 16. & Phaseolus vulgaris & Fabaceae & $\begin{array}{l}\text { Antiviral, Antioxidant and Anti- } \\
\text { inflammatory activities }\end{array}$ & $\begin{array}{l}\text { Ye et al., 2001; Oomah et } \\
\text { al., } 2010\end{array}$ \\
\hline 17. & Fraxinus sieboldiana & Oleaceae & $\begin{array}{l}\text { Anti-HIV and other Antiviral } \\
\text { activities }\end{array}$ & $\begin{array}{l}\text { Kim et al., 2001; Lin et } \\
\text { al., } 2010\end{array}$ \\
\hline 18. & Glycyrrbiza uralensis & Fabaceae & $\begin{array}{l}\text { Antiviral, Anti -inflammatory, } \\
\text { and Anti-asthmatic activities }\end{array}$ & $\begin{array}{l}\text { Alfajaro et al., 2012; Shin } \\
\text { et al., 2008; Huang et al., } \\
2019\end{array}$ \\
\hline 19. & Amaranthus tricolor & Amaranthaceae & Antioxidant activity & Pulipati et al., 2017 \\
\hline 20. & Camellia sinensise & Theaceae & $\begin{array}{l}\text { Anti-inflammatory and } \\
\text { Immunomodulatory activities }\end{array}$ & $\begin{array}{l}\text { Chattopadhyayet al., } \\
\text { 2004; Chattopadhyay et } \\
\text { al., } 2012\end{array}$ \\
\hline 21. & Andrographis paniculata & Acanthaceae & $\begin{array}{l}\text { Antiviral, Immunostimulatory, } \\
\text { Antioxidant and anti } \\
\text { inflammatory activities }\end{array}$ & $\begin{array}{l}\text { Pongtuluran and } \\
\text { Rofaani, 2015; Sheeja et } \\
\text { al., } 2006\end{array}$ \\
\hline
\end{tabular}


Ugwah-Oguejiofor and Adebisi: Potential Medicinal Plant Remedies and Their Possible Mechanisms

\begin{tabular}{|c|c|c|c|c|}
\hline 22. & Angelica keiskeia & Umbelliferae & $\begin{array}{l}\text { Anti-inflammatory and } \\
\text { Immunomodulatory activities }\end{array}$ & $\begin{array}{l}\text { Lee et al., 2010; Sudira } \\
\text { and Merdana, } 2017\end{array}$ \\
\hline 23. & Ecklonia cava & Laminariaceae & $\begin{array}{l}\text { Antimicrobial, Antioxidant and } \\
\text { Antiviral activities }\end{array}$ & $\begin{array}{l}\text { Venkatesan et al., 2016; } \\
\text { Yang et al., } 2018\end{array}$ \\
\hline 24. & Torreya nuciferad & Taxaceae & $\begin{array}{l}\text { Anti-inflammatory and } \\
\text { Antioxidant activities }\end{array}$ & $\begin{array}{l}\text { Kim et al., 2016; Jeon et } \\
\text { al., } 2009\end{array}$ \\
\hline 25. & Rheum palmatum & Polygonaceae & Antifungal activity & Shang et al., 2019 \\
\hline 26. & Withania somnifera & Solanaceae & $\begin{array}{l}\text { anti-inflammatory and anti } \\
\text { microbial activities }\end{array}$ & Dar et al., 2015 \\
\hline 27. & Strychnos usambarensis & Loganiaceae & Antimalarial activity & Frédérich et al., 2004 \\
\hline 28. & Cryptolepis sanguinolenta & Periplocaceae & Antimalarial activities & $\begin{array}{l}\text { Ansha and Mensah, } \\
2013\end{array}$ \\
\hline 29. & Teclea trichocarpa & Rutaceae & $\begin{array}{l}\text { Antiprotozoal and cytotoxic } \\
\text { activity }\end{array}$ & Mwangi et al., 2010 \\
\hline 30. & Fagara zanthoxyloides & Rutaceae & Antimalarial activity & Enechi et al., 2019 \\
\hline 31. & Ancistrocladus tanzaniensis & Acistrocladaceae & Antimalarial activity & Bringmann et al., 1999 \\
\hline 32. & Monodora angolensis & Annonaceae & Antimalarial activity & Nkunya et al., 2004 \\
\hline 33. & Toddalia asiatica & Rutaceae & $\begin{array}{l}\text { Anti-HIV and Antimalarial } \\
\text { activities }\end{array}$ & $\begin{array}{l}\text { Rashid et a 1., 1995; } \\
\text { Borah et al., } 2010\end{array}$ \\
\hline 34. & Glossocalyx brevipes & Siparunaceae & Antiplasmodial activity & Mbah et al., 2004 \\
\hline 35. & Triphyophyllum peltatum & Dioncophyllaceae & Antimalarial activity & Bringmann et al., 1997 \\
\hline 36. & Anastatica bierochuntica & Brassicaceae & $\begin{array}{l}\text { Antioxidant and antimicrobial } \\
\text { activities }\end{array}$ & Mohamed et al., 2010 \\
\hline 37. & Allium myrianthum & Liliaceae & Antioxidant activity & Petropoulos et al., 2020 \\
\hline 38. & Cichorium intybus $s^{a, c}$ & Asteraceae & $\begin{array}{l}\text { Antimalarial and } \\
\text { hepatoprotective activities }\end{array}$ & $\begin{array}{l}\text { Bischoff et al., 2004; Atta } \\
\text { et al., } 2010\end{array}$ \\
\hline 39 & Marrubium vulgara ${ }^{a, c}$ & Lamiaceae & Hypotensive activity & Bardai et al., 2001 \\
\hline 40. & Olea europaea ${ }^{a, c}$ & Oleaceae & Anti-hypertensive activity & Somova et al., 2003 \\
\hline 41. & Hibiscus sabdariffa & Malvaceae & $\begin{array}{l}\text { Anti-inflammatory and } \\
\text { Antihypertensive activities }\end{array}$ & $\begin{array}{l}\text { Dafallah and Al } \\
\text { Mustafa, 1996; } \\
\text { Onyenekwe et al., } 1999\end{array}$ \\
\hline 42. & Sonchus macrocarpus & Asteraceae & $\begin{array}{l}\text { Antioxidant and anti } \\
\text { inflammatory activities }\end{array}$ & Li and Yang, 2018 \\
\hline 43. & Tamarix nilotica & Tamaricaceae & $\begin{array}{l}\text { Antioxidant and } \\
\text { hepatoprotective activities }\end{array}$ & $\begin{array}{l}\text { AbouZid and Sleem, } \\
2011\end{array}$ \\
\hline 44. & Quercus suber & Fagaceae & Antioxidant activity & Fernandes et al., 2009 \\
\hline 45. & Artemisia berba-alba & Asteraceae & $\begin{array}{l}\text { Antioxidant and antifungal } \\
\text { activities }\end{array}$ & $\begin{array}{l}\text { Boukhennoufa et al., } \\
2020\end{array}$ \\
\hline 46. & Schinus molle & Anacardiaceae & $\begin{array}{l}\text { Anti-inflammatory and } \\
\text { Antioxidant activities }\end{array}$ & Feriani et al., 2020 \\
\hline 47. & Lepidium sativum & Brassicaceae & $\begin{array}{l}\text { Anti-inflammatory and } \\
\text { Antioxidant activities }\end{array}$ & Alqahtani et al., 2019 \\
\hline 48. & Crataegus sinaica & Rosaceae & $\begin{array}{l}\text { Antioxidant, Cytotoxic and } \\
\text { Antimicrobial activities }\end{array}$ & El-Hela et al., 2017 \\
\hline 49. & Cicer arietinum & Fabaceae & $\begin{array}{l}\text { Anti-inflammatory and } \\
\text { Antifungal activities }\end{array}$ & $\begin{array}{l}\text { Milán-Noris et al., 2018; } \\
\text { Bajwa et al., } 2006\end{array}$ \\
\hline 50. & Artemisia judaica, & Asteraceae & $\begin{array}{l}\text { Antioxidant, Antimicrobial and } \\
\text { Anti-inflammatory activities }\end{array}$ & $\begin{array}{l}\text { Nasr et al., 2020; Abu - } \\
\text { Darwish } \text { et al., } 2016\end{array}$ \\
\hline 51. & $\begin{array}{l}\text { Isatis } \\
\text { Indigotica }\end{array}$ & Brassicaceae & $\begin{array}{l}\text { Anti-inflammatory and Anti - } \\
\text { viral activities }\end{array}$ & Meng et al., 2017 \\
\hline 52. & Dioscorea batatas & Dioscoreaceae & $\begin{array}{l}\text { Anti-SARS-CoV } \\
\text { Immunomodulatory, Anti } \\
\text { inflammatory and Antioxidant } \\
\text { activities }\end{array}$ & $\begin{array}{l}\text { Wen et al., 2011; Choi et } \\
\text { al., 2004; Lim et al., } 2019\end{array}$ \\
\hline 53. & Cassia tora & Caesalpinaceae & $\begin{array}{l}\text { Anti-SARS-CoV; Anti } \\
\text { inflammatory, Antioxidant and } \\
\text { Antibacterial activities }\end{array}$ & $\begin{array}{l}\text { Wen et al., 2011; } \\
\text { Antonisamy et al., 2017; } \\
\text { Sharma et al., } 2010\end{array}$ \\
\hline 54. & $\begin{array}{l}\text { Taxillus } \\
\text { Chinensis }\end{array}$ & Loranthaceae & $\begin{array}{l}\text { Immunomodulatory, Anti } \\
\text { SARS-CoV activities }\end{array}$ & $\begin{array}{l}\text { Zhang et al., 2013; Wen } \\
\text { et al., } 2011\end{array}$ \\
\hline 55. & Cibotium barometz. & Dicksoniaceae & $\begin{array}{l}\text { Anti-SARS-CoV and Anti } \\
\text { inflammatory activities }\end{array}$ & $\begin{array}{l}\text { Wen et al., 2011; Lee et } \\
\text { al., } 2010\end{array}$ \\
\hline
\end{tabular}

$\mathrm{a}=$ Plant with PL pro activity; $\mathrm{c}=$ Plant with RdRp activity; $\mathrm{d}=$ Plant with helicase activity; e= Plants with Immunomodulatory activity; $\mathrm{f}=$ Plant with ACE2 activity 
Table 3: Medicinal plants with potential activity against SARS-CoV-2 Receptor, angiotensin-converting enzyme 2 (ACE2), binding activity

\begin{tabular}{|c|c|c|c|c|}
\hline $\mathrm{S} / \mathrm{N}$ & Medicinal plant & Family & Other Pharmacologic action & References \\
\hline 1. & Quercus infectoria & Fagaceae & $\begin{array}{l}\text { Hepatoprotective and } \\
\text { immunomodulatory activities }\end{array}$ & $\begin{array}{l}\text { Pithayanukul et al., 2009; } \\
\text { Yahya et al., } 2018\end{array}$ \\
\hline 2. & Rheum emodin & Polygonaceae & $\begin{array}{ll}\begin{array}{l}\text { Antiviral, Anti } \\
\text { inflammation activities }\end{array} & \text {-airway } \\
\end{array}$ & $\begin{array}{l}\text { Ho et al., 2007; Zhong et } \\
\text { al., } 2017\end{array}$ \\
\hline 3. & Ipomoea obscura & Convolvulaceae & $\begin{array}{l}\text { Anti-inflammatory and anti } \\
\text { tumour, Hepatoprotective and } \\
\text { antioxidant activities }\end{array}$ & $\begin{array}{l}\text { Hamsa and Kuttan, } \\
\text { 2011; Ramachandran et } \\
\text { al., } 2019\end{array}$ \\
\hline 4. & Berberis integerrima & Berberidaceae & $\begin{array}{l}\text { Anticonvulsant, Antibacterial } \\
\text { activities }\end{array}$ & $\begin{array}{l}\text { Hosseinzadeh et al., 2013; } \\
\text { Azimi et al., } 2018\end{array}$ \\
\hline 5. & Crataegus laevigata & Rosaceae & $\begin{array}{l}\text { Anti-inflammatory and Anti - } \\
\text { microbial activities }\end{array}$ & Tadić et al., 2008 \\
\hline 6. & Onopordum acanthium & Asteraceae & $\begin{array}{l}\text { Anti-inflammatory and } \\
\text { Antibacterial activities }\end{array}$ & Lajter et al., 2014 \\
\hline 7. & Cheyniana micropbylla & Myrtaceae & Antioxidant activity & Renda et al., 2018 \\
\hline 8. & Scutellaria baicalensis ${ }^{d}$ & Lamiaceae & $\begin{array}{l}\text { Anti-SARS CoV-2, Antiallergic, } \\
\text { Immunomodulatory Anti - } \\
\text { inflammatory and antioxidant } \\
\text { activities }\end{array}$ & $\begin{array}{l}\text { Liu et al.,2020; Jung } \text { et al., } \\
\text { 2012; Huang et al., 2006; } \\
\text { Yang et al., } 2007\end{array}$ \\
\hline 9. & $\begin{array}{l}\text { Veronicalina } \\
\text { Riifolia }\end{array}$ & Veronicellidae & Anti-SARS CoV activity & Goel and Goel, 2020 \\
\hline 10. & Galla chinensis & Anacardiaceae & $\begin{array}{l}\text { Antibacterial and Anti } \\
\text { inflammatory activities }\end{array}$ & Zheng et al., 2011 \\
\hline 11. & Glycyrrbizae radix & Leguminosae & $\begin{array}{l}\text { Antiviral, Antiiflammatory and } \\
\text { Antioxidant activities }\end{array}$ & $\begin{array}{l}\text { Parizipour and Shahriari, } \\
\text { 2020; Yang et al., } 2013\end{array}$ \\
\hline 12. & Polygonum multiflorum & Polygonaceae & $\begin{array}{l}\text { Immunomodulatory, } \\
\text { Antiiflammatory and } \\
\text { Antioxidant activities }\end{array}$ & $\begin{array}{l}\text { Zhang et al., 2018; Park et } \\
\text { al., 2017; Ip et al., } 1997\end{array}$ \\
\hline
\end{tabular}

Table 4: Medicinal plants with potential activity against SARS-CoV-2 Receptor, SARS CoV- PLpro activity

\begin{tabular}{|c|c|c|c|c|}
\hline $\mathrm{S} / \mathrm{N}$ & Medicinal plant & Family & Other Pharmacologic action & References \\
\hline 1. & Alnus japonica & Betulaceae & $\begin{array}{l}\text { Anti-influenza; Antioxidant and } \\
\text { Anti-inflammatory activities }\end{array}$ & $\begin{array}{l}\text { Tung et al ., 2010; } \\
\text { Ibrahim et al., } 2017\end{array}$ \\
\hline 2. & Cullen corylifolium & Leguminosae & Antiviral activity & Kim et al., 2014; \\
\hline 3. & Paulownia tomentosa & Scrophulariaceae & $\begin{array}{l}\text { Antioxidant and Anti } \\
\text { inflammatory activities }\end{array}$ & Jo and Kim, 2019 \\
\hline 4. & Salvia miltiorrbizd ${ }^{b}$ & Lamiaceae & $\begin{array}{l}\text { Antioxidant; Hepatoprotective } \\
\text { effect; Anti-HIV-1 activities }\end{array}$ & $\begin{array}{l}\text { Zhao et al., 2006; Lee et } \\
\text { al., } 2003 \text {; Abd-Elazem } e t \\
\text { al., } 2002\end{array}$ \\
\hline 5. & Tribulus terrestris & Zygophyllaceae & $\begin{array}{l}\text { Antihypertensive; } \\
\text { Anticholinergic; Antibacterial } \\
\text { activities }\end{array}$ & Ahmed et al., 2020 \\
\hline 6. & Psoralea corylifolia & Leguminosae & Anti-inflammatory activity & Neve et al., 2018 \\
\hline 7. & Cynara scolymuse & Asteracea & $\begin{array}{l}\text { Immunomodulatory, Anti - } \\
\text { inflammatory and Antioxidant } \\
\text { activity }\end{array}$ & $\begin{array}{l}\text { Hueza et al ., 2019; } \\
\text { Majeed et al., } 2015\end{array}$ \\
\hline 8. & Ephedra alata & Ephedraceae & $\begin{array}{l}\text { Anti-inflammatory and } \\
\text { Antioxidant activity }\end{array}$ & Soumaya et al., 2020 \\
\hline 9. & Salvia trilobac & Labiatae & $\begin{array}{l}\text { Anti-inflammatory and } \\
\text { Antioxidant activity }\end{array}$ & Risaliti et al., 2019 \\
\hline 10. & Centaurea furfuracea & Asteraceae & Antioxidant activity & Chemsa et al., 2018 \\
\hline 11. & Matricaria chamomillac & Asteraceae & $\begin{array}{l}\text { Anti-inflammatory, antioxidant } \\
\text { and antiviral activities }\end{array}$ & Satyal et al., 2015 \\
\hline 12. & Globularia alypum & Globulariaceae & $\begin{array}{l}\text { Antibacterial, Anti } \\
\text { inflammatory and Antioxidant } \\
\text { activities }\end{array}$ & Ghlissi et al., 2016 \\
\hline 13. & Tetraclinis articulata & Cupressaceae & $\begin{array}{l}\text { Immunomodulatory } \\
\text { Antioxidant, antibacterial, anti - } \\
\text { inflammatory activities }\end{array}$ & $\begin{array}{l}\text { Daoudi et al ., 2013; } \\
\text { Rached et al., } 2018\end{array}$ \\
\hline 14. & Podocarpus gracilior & Podocarpaceae & Antioxidant activity & Kamal et al., 2012 \\
\hline 15. & Epilobium hirsutum ${ }^{b}$ & Onagraceae & $\begin{array}{l}\text { Antiviral and Antioxidant } \\
\text { activities }\end{array}$ & $\begin{array}{l}\text { Todorov et al., 2014; } \\
\text { Karakurt et al., } 2016\end{array}$ \\
\hline 16. & Cicer arietinum ${ }^{\mathrm{b}, \mathrm{e}}$ & Fabaceae & $\begin{array}{l}\text { Antiviral and Antioxidant } \\
\text { activities }\end{array}$ & $\begin{array}{l}\text { Kan and Kartal, 2009; } \\
\text { Kou et al., } 2013\end{array}$ \\
\hline 17. & Centaurea incand ${ }^{b}$ & Asteraceae & Antioxidant activity & Bouafia et al., 2018 \\
\hline 18 & Broussonetia papyrifera & Moraceae & $\begin{array}{l}\text { Antioxidant and anti } \\
\text { inflammatory activities }\end{array}$ & Malaník et al., 2020 \\
\hline
\end{tabular}

$\mathrm{b}=$ activity against 3CLPro; $\mathrm{c}=$ Plant with RdRp activity; $\mathrm{e}=$ Plants with Immunomodulatory activity 
Table 5: Medicinal plants with potential activity against the SARS-CoV helicase

\begin{tabular}{|l|l|l|l|l|}
\hline S/N & Medicinal plant & Family & $\begin{array}{l}\text { Other Pharmacologic } \\
\text { action }\end{array}$ & References \\
\hline 1. & Aglaia perviridis & Meliaceae & $\begin{array}{l}\text { Anti-inflammatory } \\
\text { activity }\end{array}$ & An et al., 2020; \\
\hline 2. & Isatis indigoticab, & Brassicaceae & $\begin{array}{l}\text { Antiviral; Anti } \\
\text { inflammatory and } \\
\text { Antipyretic activities }\end{array}$ & $\begin{array}{l}\text { Meng } \text { et al., 2017; Ho } \text { et } \\
\text { al., 2002 }\end{array}$ \\
\hline 3. & Griffithsia spp & Wrangeliaceae & Anti-HIV1 activity & Vamvaka et al., 2016 \\
\hline
\end{tabular}

$\mathrm{b}=$ activity against $3 \mathrm{CLPro}$

Table 6: Medicinal plants against Type II Transmembrane Serine Protease (TMPRSS2)

\begin{tabular}{|l|l|l|l|l|}
\hline S/N & Medicinal plant & Family & $\begin{array}{l}\text { Other Pharmacologic } \\
\text { action }\end{array}$ & References \\
\hline 1. & Strobilanthes cusia & Acanthaceae & Antiviral activity & Tsai et al., 2020 \\
\hline 2. & Fumaria indica & Papaveraceae & $\begin{array}{l}\text { Antypyretic, Anti -cough } \\
\text { activities }\end{array}$ & Gupta et al., 2012 \\
\hline 3. & Strychnos nux-vomica & Loganiaceae & $\begin{array}{l}\text { Anti-inflammatory, } \\
\text { Antypyretic and Anti } \\
\text { oxidant activities }\end{array}$ & Eldahshan et al., 2015 \\
\hline 4. & Corydalis govaniana & Papaveraceae & $\begin{array}{l}\text { Anti-oxidant and } \\
\text { Analgesic activities }\end{array}$ & $\begin{array}{l}\text { Shrestha and Adhikari, } \\
\text { 2017; Muhammad et } \\
\text { al., 2015 }\end{array}$ \\
\hline 5. & Nerium oleander & Apocynaceae & $\begin{array}{l}\text { Anti-inflammatory, Anti - } \\
\text { poliovirus activities }\end{array}$ & $\begin{array}{l}\text { Balkan et al., 2018; } \\
\text { Sanna et al., 2019 }\end{array}$ \\
\hline 6. & Strychnos ignatii & Loganiaceae & $\begin{array}{l}\text { Anti-inflammatory } \\
\text { activity }\end{array}$ & Kim et al., 2009 \\
\hline 7. & Strychnos colubrina & Loganiaceae & Antypyretic activity & $\begin{array}{l}\text { Karthikeyan et al ., } \\
\text { 2011 }\end{array}$ \\
\hline 8. & Fumaria vaillantii & Papaveraceae & $\begin{array}{l}\text { antifungal, anti } \\
\text { inflammatory activities }\end{array}$ & Moghtader, 2013 \\
\hline 9. & Edgeworthia gardneri & Thymelaeaceae & Antidiabetic activity & Gao et al., 2016 \\
\hline
\end{tabular}

$\mathrm{a}=$ Plant with PL pro activity

Table 7. Medicinal plants against RNA-dependent RNA polymerase (RdRp)

\begin{tabular}{|c|c|c|c|c|}
\hline $\mathrm{S} / \mathrm{N}$ & Medicinal plant & Family & Other Pharmacologic action & References \\
\hline 1. & Trigonella foenum-graecume & Papilionaceae & $\begin{array}{l}\text { Immunomodulatory, } \\
\text { Antioxidant, Anti } \\
\text { inflammatory and Antipyretic } \\
\text { activities }\end{array}$ & $\begin{array}{ll}\text { Ahmadiani et al., } & \text { 2001; } \\
\text { Bhanger et al., } & 2008 ; \\
\text { Anarthe } \text { et al., } 2014 & \end{array}$ \\
\hline 2. & Eruca sativa & Brassicaceae & $\begin{array}{l}\text { Antioxidant, Antimicrobial, } \\
\text { Antiplatelet and } \\
\text { Antithrombotic activities }\end{array}$ & $\begin{array}{l}\text { Fuentes et al .,2014; } \\
\text { Koubaa et al., } 2015\end{array}$ \\
\hline 3. & Medicago sativa ${ }^{a}$ & Leguminosae & $\begin{array}{l}\text { Analgesic, anti }- \text { inflammatory, } \\
\text { Antioxidant and } \quad \text { cytotoxic } \\
\text { activities }\end{array}$ & $\begin{array}{l}\text { Seddighfar et al ., 2020; } \\
\text { Zagórska-Dziok et al., } 2020\end{array}$ \\
\hline 4. & Cleome speciese & Capparaceae & $\begin{array}{l}\text { Antimalarial, Anti } \\
\text { inflammatory, Antipyretic, } \\
\text { Antiviral and } \\
\text { immunomodulatory activities }\end{array}$ & $\begin{array}{l}\text { Abdullah et al ., 2016; } \\
\text { Samra et al., 2020; Rastogi } \\
\text { et al., } 2009\end{array}$ \\
\hline 5. & Fraxinus oxycarpa & Oleaceae & Antioxidant activity & Jiménez-López et al., 2017 \\
\hline 6. & Scrophularia sabarae & Scrophulariaceae & $\begin{array}{l}\text { Anti-inflammatory and } \\
\text { Neuroprotective activities }\end{array}$ & $\begin{array}{l}\text { Pasdaran and Hamedi, } \\
2017\end{array}$ \\
\hline 7. & Dancus carotab,e & Apiaceae & $\begin{array}{l}\text { Antiviral, Antioxidant, Anti - } \\
\text { inflammatory, and } \\
\text { Immunomodulatory activities }\end{array}$ & $\begin{array}{l}\text { Shebaby, 2014; Torky, } \\
\text { 2013; Patil et al., } 2012\end{array}$ \\
\hline 8. & Apium graveolens ${ }^{a}$ & Apiaceae & Anti-inflammatory activity & Ramezani et al., 2009 \\
\hline 9. & Houttuynia cordatab,e & Saururaceae & $\begin{array}{l}\text { Anti-inflammatory, AntiSARS } \\
\text { and Immunomodula tory } \\
\text { activities }\end{array}$ & $\begin{array}{l}\text { Choi et al., 2010; Lau et al., } \\
2008\end{array}$ \\
\hline 10. & $\begin{array}{l}\text { Sinomenium } \\
\text { acutume }\end{array}$ & Menispermaceae & Anti-inflammatory activity & Zhao et al., 2015 \\
\hline 11. & Coriolus versicolore & Polyporaceae & $\begin{array}{l}\text { Immunomodulatory, } \\
\text { antioxidant and antimicrobial, } \\
\text { Anti-HIV1 activities }\end{array}$ & $\begin{array}{l}\text { Saleh et al., 2017; Han et al., } \\
\text { 2015; Collins and Ng, } 1997\end{array}$ \\
\hline 12. & Ganoderma lucidum & Ganodermataceae & $\begin{array}{l}\text { Antioxidant, Anti } \\
\text { inflammatory } \\
\text { Immunomodulatory and } \\
\text { Antiviral activities }\end{array}$ & $\begin{array}{l}\text { Shi et al., 2013; Cai et al., } \\
\text { 2016; Zhang et al., } 2014\end{array}$ \\
\hline
\end{tabular}

$\mathrm{a}=$ Plant with PL pro activity; $\mathrm{b}=$ activity against 3CLPro 
Table 8: Medicinal plants with Immunomodulatory activities

\begin{tabular}{|c|c|c|c|c|}
\hline $\mathrm{S} / \mathrm{N}$ & Medicinal plant & Family & Other Pharmacologic action & References \\
\hline 1. & Astragalus mongholicus & Fabaceae & $\begin{array}{l}\text { Antioxidant, Anti -inflammatory } \\
\text { activities }\end{array}$ & Schinella et al., 2002 \\
\hline 2. & Lonicera japonica & Caprifoliaceae & $\begin{array}{l}\text { Antioxidant, Anti-inflammatory, } \\
\text { Antiviral activities }\end{array}$ & $\begin{array}{l}\text { Hsu et al., 2016; Liu } \\
\text { et al., } 2020\end{array}$ \\
\hline 3. & Panax ginseng & Araliaceae & $\begin{array}{l}\text { Neuroprotective and anti } \\
\text { inflammatory activities, Antiviral } \\
\text { Activities }\end{array}$ & $\begin{array}{l}\text { Kong et al., 2009; } \\
\text { Baek et al., } 2010\end{array}$ \\
\hline 4. & Astragalus membranaceus & Fabaceae & $\begin{array}{l}\text { Antiviral, Antioxidant, Anti - } \\
\text { inflammatory activities }\end{array}$ & $\begin{array}{l}\text { Khan et al. ,2019; } \\
\text { Lee et al., } 2013\end{array}$ \\
\hline 5. & Echinacea purpurea & Asteraceae & $\begin{array}{l}\text { Antioxidant, Anti -inflammatory } \\
\text { and Antiviral activities }\end{array}$ & $\begin{array}{l}\text { Aarland et al., 2017; } \\
\text { Signer et al., } 2020\end{array}$ \\
\hline 6. & Allium sativum & Alliaceae & $\begin{array}{l}\text { Antimalarial, Antioxidant, Anti- } \\
\text { inflammatory and Antiviral } \\
\text { activities }\end{array}$ & $\begin{array}{l}\text { Adebayo and } \\
\text { Motunrayo, 2018; } \\
\text { Tsai et al., 2005 }\end{array}$ \\
\hline 7. & Psidium guajava & Myrtaceae & $\begin{array}{l}\text { Anti-cough, Anti-inflammatory, } \\
\text { Antioxidant and antimicrobial } \\
\text { activities }\end{array}$ & $\begin{array}{l}\text { Fernandes et al ., } \\
\text { 2014; Jaiarj et al., } \\
\text { 1999; Sen et al., } 1995 \\
\end{array}$ \\
\hline 8. & Cymbopogon citratus & Poaceae & $\begin{array}{l}\text { Antimalaria, Antioxidant, Anti - } \\
\text { inflammatory and Antiviral } \\
\text { activities }\end{array}$ & $\begin{array}{l}\text { Tchoumbougnang et } \\
\text { al., 2005; Lu, et al., } \\
\text { 2014; Abraham - } \\
\text { Oyiguh et al., } 2019\end{array}$ \\
\hline 9. & Cinnamomum zeylanicum & Lauraceae & $\begin{array}{l}\text { Anti-inflammatory, Antioxidant } \\
\text { and Antimicrobial activities }\end{array}$ & $\begin{array}{l}\text { Joshi et al ., 2010; } \\
\text { Tepe and Ozaslan, } \\
\text { 2020; Alizadeh } \\
\text { Behbahani et al ., } \\
2020\end{array}$ \\
\hline 10. & Acacia concinna & Fabaceae & $\begin{array}{l}\text { Antibacterial, Anti -coagulant, } \\
\text { Anti-platelet and Anti } \\
\text { thrombotic activities }\end{array}$ & $\begin{array}{l}\text { Todkar et al., 2010; } \\
\text { Boonmee et al., } 2017\end{array}$ \\
\hline 11. & Lawsonia inermis & Lythraceae & $\begin{array}{l}\text { Anti-inflammatory, antipyretic, } \\
\text { Antimicrobial Antimalarial } \\
\text { activities }\end{array}$ & $\begin{array}{l}\text { Alia et al., 1995; El- } \\
\text { Hag et al., 2007; } \\
\text { Afolayan et al., 2016 }\end{array}$ \\
\hline 12. & Piper longum & Piperaceae & $\begin{array}{l}\text { Antioxidant, Anti -inflammatory } \\
\text { and Antiallergic activities }\end{array}$ & $\begin{array}{l}\text { Jin et al ., 2013; } \\
\text { Dahanukar et al., } \\
1984\end{array}$ \\
\hline 13. & Gelidium amansii & Gelidiaceae & $\begin{array}{l}\text { Anti-inflammatory, } \\
\text { Antibacterial and Antifungal } \\
\text { activities }\end{array}$ & $\begin{array}{l}\text { Park and Yoon, } \\
\text { 2018; Nagalingam et } \\
\text { al., 2019 }\end{array}$ \\
\hline 14. & Petroselinum crispum & Apiaceae & $\begin{array}{l}\text { Antioxidant, Anti-inflammatory, } \\
\text { Antihypertensive and } \\
\text { Antibacterial activities }\end{array}$ & $\begin{array}{l}\text { Petrolini, et al., } \\
\text { 2013; Ajebli et al., } \\
\text { 2019; Slighoua et al., } \\
2020\end{array}$ \\
\hline 15. & Plantago major & Plantaginaceae & $\begin{array}{l}\text { Anti-inflammatory, Antioxidant } \\
\text { and Antiviral activities }\end{array}$ & $\begin{array}{l}\text { Zubair et al., 2019; } \\
\text { Stanisavljević et al., } \\
\text { 2008; Chiang et al., } \\
2002\end{array}$ \\
\hline 16. & Adenocarpus mannii & Faboideae & $\begin{array}{l}\text { Antioxidant and Antimicrobial } \\
\text { activities }\end{array}$ & Ndjateu et al., 2014 \\
\hline 17. & Caucalis melanantha & Umbelliferae & Antibacterial activity & Djeussi et al., 2016 \\
\hline 18. & Ocimum gratissimum & Lamiaceae & $\begin{array}{l}\text { Antimalarial, Anti } \\
\text { inflammatory, Antioxidant and } \\
\text { Antimicrobial activities }\end{array}$ & $\begin{array}{l}\text { Tchoumbougnang } \\
\text { et al., 2005; Joshi, } \\
2013 \\
\end{array}$ \\
\hline 19. & Asystasia intrusa & Acanthaceae & $\begin{array}{l}\text { Anti-inflammatory and } \\
\text { Antimicrobial Activities }\end{array}$ & $\begin{array}{l}\text { West et al ., 2011; } \\
\text { Dian, } 2016\end{array}$ \\
\hline 20. & Clematis chinensis & Ranunculaceae & $\begin{array}{l}\text { Anti-inflammatory and } \\
\text { Antioxidant activities }\end{array}$ & $\begin{array}{l}\text { Peng et al ., 2012; } \\
\text { Chen et al., 2005 }\end{array}$ \\
\hline 21. & Pouteria cambodiana & Sapotaceae & Antioxidant activity & $\begin{array}{l}\text { Chaisri and } \\
\text { Laoprom, } 2017\end{array}$ \\
\hline 22. & Clausena excavata & Rutaceae & $\begin{array}{l}\text { Anti-HIV-1, Antiplatelet } \\
\text { activity, Anti -inflammatory and } \\
\text { Antioxidant activities }\end{array}$ & $\begin{array}{l}\text { Kongkathip et al., } \\
\text { 2005; Wu et al., } \\
\text { 1994; Albaayit et al., } \\
2020\end{array}$ \\
\hline 23. & Limoniastrum guyonianum & Plumbaginaceae & $\begin{array}{l}\text { Anti-inflammatory, Antioxidant } \\
\text { and Antimicrobial activities }\end{array}$ & $\begin{array}{l}\text { Krifa et al ., 2015; } \\
\text { Bouzidi et al., 2016 }\end{array}$ \\
\hline 24. & Codium fragile & Codiaceae & $\begin{array}{l}\text { Anti-inflammatory, Antioxidant, } \\
\text { Thrombolytic and Antiviral } \\
\text { activities }\end{array}$ & $\begin{array}{ll}\text { Choi et al., 2013; } & \text { 2009; } \\
\text { Koz et al., } & \text { 2009; } \\
\text { Ohta et al., } & \text { Han } \text { et al., } 2010\end{array}$ \\
\hline 25. & Acacia catechu & Mimosoideae & $\begin{array}{l}\text { Anti-inflammatory, Antioxidant, } \\
\text { Antiallergic and Antiviral } \\
\text { activities }\end{array}$ & $\begin{array}{l}\text { Stohs and Bagchi, } \\
\text { 2015; Patel and } \\
\text { Patel, 2019; Gupta } \\
\text { and Chaphalkar, } \\
\text { 2016 }\end{array}$ \\
\hline
\end{tabular}




\section{CONCLUSION AND PROSPECTS}

In the present review, we have shown the various medicinal plants which have been utilised in the prevention and treatment of COVID-19. Majority of the plants have also been shown to possess other pharmacological activities which may contribuite to their ability to alleviate the symptoms and treat coronavirus disease. This medicinal plants use has been regarded among the principal factors that contributed to the containment of the COVID-19 in China (Salzberger et al., 2020). Existing information have shown that the possible mechanism of action of anti-COVID-19 medicinal plants were inhibition of 3-chymotrypsin- like protease (3CLpro), papain like protease (PLpro), RNAdependent RNA polymerase (RdRp), angiotensinconverting enzyme 2 (ACE2) and immunomodulatory activities. These proposed mechanisms target multiple components pathways in the life cycle of SARS-CoV-2 for the treatment of COVID-19. However, the bulk of the understanding of the mechanisms of medicinal plants is mainly produced following virtual simulations (molecular docking and network pharmacology analysis). In order to confirm these predicted mechanisms, it is of paramount importance that well designed experiments (both in vitro cell and in vivo animal studies) be conducted to validate these predictions. Finally, tissue samples as well as the biofluids from medicinal plant-treated COVID19 patients should be collected and analysed using appropriate instruments and controlled clinical trial parameters to further validate the proposed possible mechanisms.

\section{REFERENCES}

Aarland, R.C., Bañuelos-Hernández, A.E., Fragoso-Serrano, M., Sierra-Palacios, E.D.C., Díaz de León-Sánchez, F., PérezFlores, L.J., Rivera-Cabrera, F. and Mendoza-Espinoza, J.A., 2017. Studies on phytochemical, antioxidant, antiinflammatory, hypoglycaemic and antiproliferative activities of Echinacea purpurea and Echinacea angustifolia extracts. Pharmacentical biology, 55(1), pp.649-656.

Abd-Elazem, I.S., Chen, H.S., Bates, R.B. and Huang, R.C.C., 2002. Isolation of two highly potent and non-toxic inhibitors of human immunodeficiency virus type 1 (HIV-1) integrase from Salvia miltiorrhiza. Antiviral research, 55(1), pp.91-106.

Abdullah, W., Elsayed, W.M., Abdelshafeek, K.A., Nazif, N.M. and Singab, A.N.B., 2016. Chemical constituents and biological activities of Cleome genus: A brief review. Int. J. Pharmacogn. Phytochem. Res, 8, pp.777787.

Abedini, A., Roumy, V., Mahieux, S., Biabiany, M., Standaert-Vitse, A., Rivière, C., Sahpaz, S., Bailleul, F., Neut, C. and Hennebelle, T., 2013. Rosmarinic acid and its methyl ester as antimicrobial components of the hydromethanolic extract of Hyptis atrorubens Poit.(Lamiaceae). EvidenceBased Complementary and Alternative Medicine, 2013.

AbouZid, S. and Sleem, A., 2011. Hepatoprotective and antioxidant activities of Tamarix nilotica flowers. Pharmacentical biology, 49(4), pp.392-395.

Abraham-Oyiguh, J., Zakka, A.W., Onwuatuegwu, J.T.C., Sulaiman, L.K. and Muhammad, S.Y., 2019. In-ovo antiviral assay of methanolic leaf extract of Cymbopogon citratus (Lemon grass) on Newcastle disease virus. Access Microbiology, 1(1A), p.25.

Abu-Darwish, M.S., Cabral, C., Gonçalves, M.J., Cavaleiro, C., Cruz, M.T., Zulfiqar, A., Khan, I.A., Efferth, T. and Salgueiro, L., 2016. Chemical composition and biological activities of Artemisia judaica essential oil from southern desert of Jordan. Journal of ethnopharmacology, 191, pp.161-168.

Adebayo, N.S. and Motunrayo, O., 2018. Evaluation of antiplasmodial potential of Aloe barbadensis and Allium sativum on plasmodium berghei-infected mice. Journal of Medicinal Plants Research, 12(22), pp.320-324.

Afolayan, F.I., Adegbolagun, O.M., Irungu, B., Kangethe, L., Orwa, J. and Anumudu, C.I., 2016. Antimalarial actions of Lawsonia inermis, Tithonia diversifolia and Chromolaena odorata in combination. Journal of ethnopharmacology, 191, pp.188- 
194.

Ahmadiani, A., Javan, M., Semnanian, S., Barat, E. and Kamalinejad, M., 2001. Antiinflammatory and antipyretic effects of Trigonella foenum-graecum leaves extract in the rat. Journal of ethnopharmacology, 75(23), pp.283-286.

Ahmed, S., Khan, A.A., Yadav, P., Akhtar, J., Akram, U. and Shamim, L.F. 2020. Gokhru (Tribulus terrestris Linn.): Pharmacological actions and therapeutic applications: A Review. International Journal of HerbalMedicine, 8(4), pp. 25-29.

Ajebli, M. and Eddouks, M., 2019. Antihypertensive activity of Petroselinum crispum through inhibition of vascular calcium channels in rats. Journal of ethnopharmacology, 242, p.112039.

Akhtar, S., 2010. Use of Tinospora cordifolia in HIV infection. Indian Journal of Pharmacology, 42(1), p.57

Albaayit, S.F.A., Rasedee, A., Abdullah, N. and Abba, Y., 2020. Methanolic extract of Clausena excavata promotes wound healing via antiinflammatory and antiapoptotic activities. Asian Pacific Journal of Tropical Biomedicine, 10(5), p.232.

Alfajaro, M.M., Kim, H.J., Park, J.G., Ryu, E.H., Kim, J.Y., Jeong, Y.J., Kim, D.S., Hosmillo, M., Son, K.Y., Lee, J.H. and Kwon, H.J., 2012. Anti-rotaviral effects of Glycyrrhiza uralensis extract in piglets with rotavirus diarrhea. Virology journal, 9(1), p.310.

Alia, B.H., Bashir, A.K. and Tanira, M.O.M., 1995. Anti-inflammatory, antipyretic, and analgesic effects of Lawsonia inermis L.(henna) in rats. Pharmacology, 51(6), pp.356-363.

Alizadeh Behbahani, B., Falah, F., Lavi Arab, F., Vasiee, M. and Tabatabaee Yazdi, F., 2020. Chemical Composition and Antioxidant, Antimicrobial, and Antiproliferative Activities of Cinnamomum zeylanicum Bark Essential Oil. Evidence-Based Complementary and Alternative Medicine, 2020.

Alqahtani, F.Y., Aleanizy, F.S., Mahmoud, A.Z., Farshori, N.N., Alfaraj, R., Al-sheddi, E.S. and Alsarra, I.A., 2019. Chemical composition and antimicrobial, antioxidant, and anti-inflammatory activities of Lepidium sativum seed oil. Saudi journal of biological sciences, 26(5), pp.1089-1092.

An, F.L., Xu, W.J., Yang, M.H., Luo, J. and Kong, L.Y., 2020. Anti-inflammatory flavagline glycosides and putrescine bisamides from Aglaia perviridis leaves. Tetrahedron, p.131257.

Anarthe, S.J., Sunitha, D. and Raju, M.G., 2014. Immunomodulatory activity for methanolic extract of Trigonella foenum graecum whole plant in wistar albino rats. Am J Phytomed Clin Ther, 2(9), pp.10811092.

Andrighetti-Fröhner, C., Sincero, T.C.M., Da Silva, A.C., Savi, L.A., Gaido, C.M., Bettega, J.M.R., Mancini, M., De Almeida, M.T.R., Barbosa, R.A., Farias, M.R. and Barardi, C.R.M., 2005. Antiviral evaluation of plants from Brazilian atlantic tropical forest. Fitoterapia, 76(3-4), pp.374-378.

Ang, L., Lee, H.W., Choi, J.Y., Zhang, J. and Lee, M.S., 2020. Herbal medicine and pattern identification for treating COVID-19: a rapid review of guidelines. Integrative Medicine Research, 9(2), June 2020, p.100407.

Ansha, C. and Mensah, K.B., 2013. A review of the anticancer potential of the antimalarial herbal Cryptolepis sanguinolenta and its major alkaloid cryptolepine. Ghana medical journal, 47(3), pp.137-147.

Antonisamy, P., Dhanasekaran, M., Kim, H.R., Jo, S.G., Agastian, P. and Kwon, K.B., 2017. Anti-inflammatory and analgesic activity of ononitol monohydrate isolated from Cassia tora L. in animal models. Saudi journal of biological sciences, 24(8), pp.19331938.

Asmilia, N., Sutriana, A., Aliza, D. and Sudril, N., 2020. Anti-inflammatory Activity of Ethanol Extract from Malacca Leaves (Phyllanthus emblica) in Carrageenan Induced Male Mice. In E3S Web of Conferences (Vol. 151, p. 01066). EDP Sciences.

Atta, A.H., Elkoly, T.A., Mouneir, S.M., Kamel, G., Alwabel, N.A. and Zaher, S., 2010. 
Hepatoprotective effect of methanol extracts of Zingiber officinale and Cichorium intybus. Indian journal of pharmacentical sciences, 72(5), p.564.

Azimi, G., Hakakian, A., Ghanadian, M., Joumaa, A. and Alamian, S., 2018. Bioassaydirected isolation of quaternary benzylisoquinolines from Berberis integerrima with bactericidal activity against Brucella abortus. Research in PharmaceuticalSciences, 13(2), p.149.

Badam, L., Joshi, S.P. and Bedekar, S.S., 1999. 'In vitro'antiviral activity of neem (Azadirachta indica. A. Juss) leaf extract against group $\mathrm{B}$ coxsackieviruses. The Journal of communicable diseases, 31(2), pp.7990.

Baek, S.H., Lee, J.G., Park, S.Y., Bae, O.N., Kim, D.H. and Park, J.H., 2010. Pectic polysaccharides from Panax ginseng as the antirotavirus principals in ginseng. Biomacromolecules, 11(8), pp.2044-2052.

Bajwa, R., Anjum, T., Shafique, S. and Shafique, S., 2006. Evaluation of antifungal activity of Cicer arientinum L. Pakistan Journal of Botany, 38(1), p.175.

Balkan, İ.A., Gören, A.C., Kırmızıbekmez, H. and Yeşilada, E., 2018. Evaluation of the in vitro anti-inflammatory activity of Nerium oleander L. flower extracts and activity-guided isolation of the active constituents.

Balkrishna A, Pokhrel S, Singh J, Varshney A 2020. Withanone from Withania somnifera May Inhibit Novel Coronavirus (COVID-19) Entry by Disrupting Interactions between Viral S-Protein Receptor Binding Domain and Host ACE2 Receptor. Research Square; DOI: $10.21203 /$ rs.3.rs-17806/v1.

Bardai, S.E., Lyoussi, B., Wibo, M. and Morel, N., 2001. Pharmacological evidence of hypotensive activity of Marrubium vulgare and Foeniculum vulgare in spontaneously hypertensive rat. Clinical and experimental hypertension, 23(4), pp.329343.

Beghelli, D., Isani, G., Roncada, P., Andreani, G., Bistoni, O., Bertocchi, M., Lupidi, G. and Alunno, A., 2017. Antioxidant and ex vivo immune system regulatory properties of Boswellia serrata extracts. Oxidative
Medicine and Cellular Longevity, 2017.

Benarba, B. and Pandiella, A., 2020. Medicinal plants as sources of active molecules against COVID-19. Frontiers in Pharmacology, 11.

Bhanger, M.I., Bukhari, S.B. and Memon, S., 2008. Antioxidative activity of extracts from a Fenugreek seeds (Trigonella foenumgraecum). Pakistan Journal of Analytical \& Environmental Chemistry, 9(2), p.6.

Bhuiyan, F.R., Howlader, S., Raihan, T. and Hasan, M., 2020. Plants Metabolites: Possibility of Natural Therapeutics against the COVID-19 Pandemic. Frontiers in Medicine, 7,p.444.

Bischoff, T.A., Kelley, C.J., Karchesy, Y., Laurantos, M., Nguyen-Dinh, P. and Arefi, A.G., 2004. Antimalarial activity of Lactucin and Lactucopicrin: sesquiterpene lactones isolated from Cichorium intybus L. Journal of ethnopharmacology, 95(2-3), pp.455-457.

Bleyzac, N., Goutelle, S., Bourguignon, L. and Tod, M., 2020. Azithromycin for COVID19: More Than Just an Antimicrobial? Clinical drug investigation. Jun 12: 1-4. doi: 10.1007/s40261-020-009333 [Epub ahead of print]

Boonmee, S. and Kato-Noguchi, H., 2017. Allelopathic activity of Acacia concinna pod extracts. Emirates Journal of Food and Agriculture, pp.250-255.

Borah, R., Kalita, M.C., Kar, A. and Talukdar, A.K., 2010. Larvicidal efficacy of Toddalia asiatica (Linn.) Lam against two mosquito vectors Aedes aegypti and Culex quinquefasciatus. African Journal of Biotechnology, 9(17), pp.2527-2530.

Bouafia, M., Benarfa, A., Gourine, N. and Yousfi, M., 2020. Seasonal variation of fatty acid composition, tocopherol content and antioxidant activity of lipid extracts from Centaurea sp. Food Bioscience, 37, p.100728.

Boukhatem, M.N. and Setzer, W.N., 2020. Aromatic Herbs, Medicinal Plant-Derived Essential Oils, and Phytochemical Extracts as Potential Therapies for Coronaviruses: Future Perspectives. Plants, 9(6), p.800. 
Boukhennoufa, A., Benmaghnia, S., Meddah, B. and Meddah, A.T.T., 2020. Antioxidant activity of extracts formulated from Citrus aurantium and Artemisia herba alba. European Journal of Biological Research, 10(4), pp.343-351.

Bouzidi, A., Benzarti, A., El Arem, A., Mahfoudhi, A., Hammami, S., Gorcii, M., Mastouri, M., Hellal, A.N. and Zine, M., 2016. Chemical composition, antioxidant and antimicrobial effects of Tunisian Limoniastrum guyonianum Durieu ex Boiss extracts. Pak J Pharm Sci, 29(4), pp.1299-305.

Bringmann, G., Saeb, W., Assi, L.A., Francois, G., Narayanan, A.S., Peters, K. and Peters, E.M., 1997. Betulinic acid: isolation from Triphyophyllum peltatum and Ancistrocladus heyneanus, antimalarial activity, and crystal structure of the benzyl ester. Planta medica, 63(03), pp.255-257.

Bringmann, G., Teltschik, F., Michel, M., Busemann, S., Rückert, M., Haller, R., Bär, S., Robertson, S.A. and Kaminsky, R., 1999. Ancistrobertsonines B, C, and D as well as 1,2-didehydroancistrobertsonine D from Ancistrocladus robertsoniorum. Phytochemistry, 52(2), pp.321-332.

Cai, Z., Wong, C.K., Dong, J., Jiao, D., Chu, M., Leung, P.C., San Lau, C.B., Lau, C.P., Tam, L.S. and Lam, C.W.K., 2016. Antiinflammatory activities of Ganoderma lucidum (Lingzhi) and San-Miao-San supplements in MRL/lpr mice for the treatment of systemic lupus erythematosus. Chinese medicine, 11(1), p.23.

Carrasco, F.R., Schmidt, G., Romero, A.L., Sartoretto, J.L., Caparroz-Assef, S.M., Bersani-Amado, C.A. and Cuman, R.K.N., 2009. Immunomodulatory activity of Zingiber officinale Roscoe, Salvia officinalis L. and Syzygium aromaticum L. essential oils: evidence for humor-and cell-mediated responses. Journal of Pharmacy and Pharmacology, 61(7), pp.961-967.

CDC $\left(2020^{2}\right)$. Coronavirus Disease (2019). Older adults. https://www.cdc.gov/ coronavirus/2019-ncov/need-extraprecautions/older-adults.html. Accessed $14^{\text {th }}$ October, 2020.

CDC $\left(2020^{b}\right)$. Coronavirus Disease (2019). People with Certain Medical Conditions https://www.cdc.gov/coronavirus/2019 -ncov/need-extra-precautions/peoplewith-medical-conditions.html. Accessed $14^{\text {th }}$ October, 2020.

CDC (2021). Authorized and Recommended Vaccines. Different COVID-19 Vaccines | CDC. Accessed 22 ${ }^{\text {nd }}$ March, 2021.

Chaccour, C., Abizanda, G., Irigoyen-Barrio, Á., Casellas, A., Aldaz, A., Martínez-Galán, F., Hammann, F. and Gil, A.G., 2020. Nebulized ivermectin for COVID-19 and other respiratory diseases, a proof of concept, dose-ranging study in rats. Scientific Reports, 10(1), pp.1-11.

Chaisri, P. and Laoprom, N., 2017. Antioxidant Properties and Total Phenolic Content of Selected Traditional Thai Medicinal Plants. Thai Pharmaceutical and Health Science Journal-วารสาร ไทย เภสัชศาสตร์และ วิทยาการ สุขภาพ, 12(1), pp.10-18.

Chan, J.F.W., Kok, K.H., Zhu, Z., Chu, H., To, K.K.W., Yuan, S. and Yuen, K.Y., $2020^{\circ}$. Genomic characterization of the 2019 novel human-pathogenic coronavirus isolated from a patient with atypical pneumonia after visiting Wuhan. Emerging microbes \& infections, 9(1), pp.221-236.

Chan, K.W., Wong, V.T. and Tang, S.C.W., 2020 COVID-19: An update on the epidemiological, clinical, preventive and therapeutic evidence and guidelines of integrative Chinese-Western medicine for the management of 2019 novel coronavirus disease. The American journal of Chinese medicine, 48(03), pp.737-762.

Chattopadhyay, C., Chakrabarti, N., Chatterjee, M., Mukherjee, S., Sarkar, K. and Chaudhuri, A.R., 2012. Black tea (Camellia sinensis) decoction shows immunomodulatory properties on an experimental animal model and in human peripheral mononuclear cells. Pharmacognosy research, 4(1), p.15.

Chattopadhyay, P., Besra, S.E., Gomes, A., Das, M., Sur, P., Mitra, S. and Vedasiromoni, J.R., 2004. Anti-inflammatory activity of tea (Camellia sinensis) root extract. Life 
sciences, 74(15), pp.1839-1849.

Chemsa, A.E., Zellagui, A., Öztürk, M., Ebru, E.R.O.L., Ceylan, O. and Duru, M.E., 2018. The chemical composition of Centaurea furfuracea Coss. and Dur. essential oil with antioxidant, anticholinesterase and antibiofilm activities. Journal of ongoing chemical research, 3(2), pp.54-63.

Chen, Y., Sun, Y. and Fang, W., 2005. Study on antioxidant activity of Clematis chinensis Osbeck polysaccharide. China Journal of Traditional Chinese Medicine and Pharmacy, (03).

Chen, Z. and Nakamura, T., 2004. Statistical evidence for the usefulness of Chinese medicine in the treatment of SARS. Phytotherapy Research: An International Journal Devoted to Pharmacological and Toxicological Evaluation of Natural Product Derivatives, 18(7), pp.592-594.

Chiang, L.C., Chiang, W., Chang, M.Y., Ng, L.T. and Lin, C.C., 2002. Antiviral activity of Plantago major extracts and related compounds in vitro. Antiviral research, 55(1), pp.53-62.

Chiba, S., 2020. Effect of early oseltamivir on COVID-19-suspected outpatients without hypoxia. Research square DOI: https://doi.org/10.21203/rs.3.rs$33046 / v 1$ [Epub ahead of print]

Cho, J.K., Curtis-Long, M.J., Lee, K.H., Kim, D.W., Ryu, H.W., Yuk, H.J. and Park, K.H., 2013. Geranylated flavonoids displaying SARS-CoV papain-like protease inhibition from the fruits of Paulownia tomentosa. Bioorganic \& medicinal chemistry, 21(11), pp.3051-3057.

Choi, E.M., Koo, S.J. and Hwang, J.K., 2004. Immune cell stimulating activity of mucopolysaccharide isolated from yam (Dioscorea batatas). Journal of Ethnopharmacology, 91(1), pp.1-6.

Choi, J.H., Sapkota, K., Park, S.E., Kim, S. and Kim, S.J., 2013. Thrombolytic, anticoagulant and antiplatelet activities of codiase, a bi-functional fibrinolytic enzyme from Codium fragile. Biochimie, 95(6), pp.1266-1277.
Choi, J.Y., Lee, J., Lee, J.B., Yun, S.J. and Lee, S.C., 2010. Anti-inflammatory activity of Houttuynia cordata against lipoteichoic acid-induced inflammation in human dermal fibroblasts. Chonnam Medical Journal, 46(3), pp.140-147.

Choi, Y.H., Yan, G.H., Chai, O.H. and Song, C.H., 2010. Inhibitory effects of curcumin on passive cutaneous anaphylactoid response and compound 48/80-induced mast cell activation. Anatomy \& cell biology, 43(1), pp.36-43.

Chu, D.K., Pan, Y., Cheng, S., Hui, K.P., Krishnan, P., Liu, Y., Ng, D.Y., Wan, C.K., Yang, P., Wang, Q., 2020. Molecular diagnosis of a novel coronavirus (2019-nCoV) causing an outbreak of pneumonia. Clin. Chem. 66 (4), 549-555.

Collins, R.A. and Ng, T.B., 1997. Polysaccharopeptide from Coriolus versicolor has potential for use against human immunodeficiency virus type 1 infection. Life Sciences, 60(25), pp.PL383PL387.

da Silva, S.J.R., da Silva, C.T.A., Mendes, R.P.G. and Pena, L., 2020. Role of Nonstructural Proteins in the Pathogenesis of SARS-CoV-2. Journal of Medical Virology.

Dafallah, A.A. and Al-Mustafa, Z., 1996. Investigation of the anti-inflammatory activity of Acacia nilotica and Hibiscus sabdariffa. The American journal of Chinese medicine, 24(03n04), pp.263-269.

Dahanukar, S.A. and Karandikar, S.M., 1984. Evaluation of anti-allergic activity of Piper longum. Indian Drugs, 21 (9), pp.377383.

Daoudi, A., Aarab, L. and Abdel-Sattar, E., 2013. Screening of immunomodulatory activity of total and protein extracts of some Moroccan medicinal plants. Toxicology and industrial health, 29(3), pp.245-253.

Dar, N.J., Hamid, A. and Ahmad, M., 2015. Pharmacologic overview of Withania somnifera, the Indian ginseng. Cellular and molecular life sciences, 72(23), pp.4445-4460.

De Clercq, E., 2000. Current lead natural products for the chemotherapy of human immunodeficiency virus (HIV) infection. 
Medicinal research reviews, 20(5), pp.323-349.

De Clercq, E., 2019. New nucleoside analogues for the treatment of hemorrhagic fever virus infections. Chemistry-An Asian Journal, 14(22), pp.3962-3968.

Deshpande, P.K., Gothalwal, R. and Pathak, A.K., 2014. Phytochemical analysis and evaluation of antimalarial activity of Azadirachta indica. The Pharma Innovation, 3(9, Part A), p.12.

Dian, N., 2016. Studi Kandungan Zat Makanan Dan

Komponen Serat Tanaman Ara Sungsang (Asystasia gangetica L.) Sebagai Pakan Ternak Kambing Di Wilayah Payakumbuh (Doctoral dissertation, Universitas Andalas).

Djeussi, D.E., Noumedem, J.A., Ngadjui, B.T. and Kuete, V., 2016. Antibacterial and antibiotic-modulation activity of six Cameroonian medicinal plants against Gram-negative multi-drug resistant phenotypes. BMC complementary and alternative medicine, 16(1), p.124.

Eldahshan, O.A. and Abdel-Daim, M.M., 2015. Phytochemical study, cytotoxic, analgesic, antipyretic and anti-inflammatory activities of Strychnos nux-vomica. Cytotechnology, 67(5), pp.831-844.

El-Hag, A.G., Al-Jabri, A.A. and Habbal, O.A., 2007. Antimicrobial properties of Lawsonia inermis (henna): a review. Australian Journal of Medical Herbalism, 19(3), p.114.

El-Hela, A.A., Abdelhady, N.M., Gonaid, M.H. and Badr, K.A., 2017. Antioxidant, cytotoxic and antimicrobial activities of crude and green synthesized silver nanoparticles' extracts of Crataegus sinaica Boiss. leaves. International Journal of Pharmaceutical Sciences Review and Research, 45(1), pp.223-232.

Enechi, O.C., Amah, C.C., Okagu, I.U., Ononiwu, C.P., Azidiegwu, V.C., Ugwuoke, E.O., Onoh, A.P. and Ndukwe, E.E., 2019. Methanol extracts of Fagara zanthoxyloides leaves possess antimalarial effects and normalizes haematological and biochemical status of Plasmodium berghei-passaged mice. Pharmacentical biology, 57(1), pp.577-585.

Esakandari, H., Nabi-Afjadi, M., Fakkari-Afjadi,
J., Farahmandian, N., Miresmaeili, S.M. and Bahreini, E., 2020. A comprehensive review of COVID-19 characteristics. Biological Procedures Online, 22, pp.1-10.

Ezzat, S.M., Ezzat, M.I., Okba, M.M., Menze, E.T. and Abdel-Naim, A.B., 2018. The hidden mechanism beyond ginger (Zingiber officinale Rosc.) potent in vivo and in vitro anti-inflammatory activity. Journal of ethnopharmacology, 214, pp.113-123.

FDA $\left(2020^{2}\right)$. United States Food and Drug Administration. Coronavirus Treatment Acceleration Program (CTAP) https://www.fda.gov/drugs/coronavirus -covid-19-drugs/coronavirus-treatmentacceleration-program-ctap. Accessed $20^{\text {th }}$ October, 2020.

FDA $\left(2020^{b}\right)$. United States Food and Drug Administration. Coronavirus (COVID19) Update: FDA Issues Emergency Use Authorization for Potential COVID-19 Treatment. https://www.fda.gov/newsevents / press-announcements / coronavirus-covid-19-update-fda-issuesemergency-use-authorization-potentialcovid-19-treatment.

FDA $\left(2020^{\circ}\right)$. United States Food and Drug Administration. FDA Issues Emergency Use Authorization for Convalescent Plasma as Potential Promising COVID-19 Treatment, Another Achievement in Administration's Fight Against Pandemic. https://www.fda. gov/news-events/pressannouncements/fda-issues-emergencyuse-authorization-convalescent-plasmapotential-promising-covid-19-treatment. Accessed $20^{\text {th }}$ October, 2020.

Feriani, A., Tir, M., Hamed, M., Sila, A., Nahdi, S., Alwasel, S., Harrath, A.H. and Tlili, N., 2020. Multidirectional insights on polysaccharides from Schinus terebinthifolius and Schinus molle fruits: Physicochemical and functional profiles, in vitro antioxidant, anti-genotoxicity, antidiabetic, and antihemolytic capacities, and in vivo anti-inflammatory and antinociceptive properties. International Journal of BiologicalMacromolecules. 
Fernandes, A., Fernandes, I., Cruz, L., Mateus, N., Cabral, M. and de Freitas, V., 2009. Antioxidant and biological properties of bioactive phenolic compounds from Quercus suber L. Journal of agricultural and food chemistry, 57(23), pp.11154-11160.

Fernandes, M.R.V., Dias, A.L.T., Carvalho, R.R., Souza, C.R.F. and Oliveira, W.P., 2014. Antioxidant and antimicrobial activities of Psidium guajava L. spray dried extracts. Industrial Crops and Products, 60, pp.39-44.

Frédérich, M., Tits, M., Goffin, E., Philippe, G., Grellier, P., De Mol, P., Hayette, M.P. and Angenot, L., 2004. In vitro and in vivo antimalarial properties of isostrychnopentamine, an indolomonoterpenic alkaloid from Strychnos usambarensis. Planta medica, 70(06), pp.520-525.

Fuentes, E., Alarcón, M., Fuentes, M., Carrasco, G. and Palomo, I., 2014. A novel role of Eruca sativa Mill.(rocket) extract: Antiplatelet (NF- $x \mathrm{~B}$ inhibition) and antithrombotic activities. Nutrients, 6(12), pp.5839-5852.

Gaire, B.P. and Subedi, L., 2014. Phytochemistry, pharmacology and medicinal properties of Phyllanthus emblica Linn. Chinese journal of integrative medicine, pp.1-8.

Gao, D., Zhang, Y.L., Yang, F.Q., Li, F., Zhang, Q.H. and Xia, Z.N., 2016. The flower of Edgeworthia gardneri (wall.) Meisn. suppresses adipogenesis through modulation of the AMPK pathway in 3T3-L1 adipocytes. Journal of ethnopharmacology, 191, pp.379-386.

Gao, J., Tian, Z. and Yang, X., 2020.

Breakthrough: Chloroquine phosphate has shown apparent efficacy in treatment of COVID-19 associated pneumonia in clinical studies. Bioscience trends.14(1):7273. doi: 10.5582/bst.2020.01047.

Ghlissi, Z., Kallel, R., Sila, A., Harrabi, B., Atheymen, R., Zeghal, K., Bougatef, A. and Sahnoun, Z., 2016. Globularia alypum methanolic extract improves burn wound healing process and inflammation in rats and possesses antibacterial and antioxidant activities. Biomedicine \& Pharmacotherapy, 84, pp.1488-1495.
Ghoke, S. S., R. Sood, N. Kumar, A. K. Pateriya, S. Bhatia, A. Mishra, R. Dixit et al. "Evaluation of antiviral activity of Ocimum sanctum and Acacia arabica leaves extracts against H9N2 virus using embryonated chicken egg model." BMC complementary and alternative medicine 18, no. 1 (2018): 174.

Goel, S. and Goel, A., 2020. COVID-19 evolution and alternative medicine-A review. J Pure ApplMicrobiol, 14(suppl 1), pp.841-848.

Gupta, A. and Chaphalkar, S.R., 2016. Cytotoxic and anti-viral activity of Acacia catechu on human peripheral blood mononuclear cells. Indonesian Journal of Pharmacy, 27(2), p.111.

Gupta, P.C., Sharma, N. and Rao, C.V., 2012. A review on ethnobotany, phytochemistry and pharmacology of Fumaria indica (Fumitory). Asian Pacific Journal of Tropical Biomedicine, 2(8), pp.665-669.

Gyebi, G.A., Ogunro, O.B., Adegunloye, A.P., Ogunyemi, O.M. and Afolabi, S.O., 2020. Potential inhibitors of coronavirus 3chymotrypsin-like protease (3CLpro): An in silico screening of alkaloids and terpenoids from African medicinal plants. Journal of Biomolecular Structure and Dynamics, (just-accepted), pp.1-19.

Hamsa, T.P. and Kuttan, G., 2011. Evaluation of the anti-inflammatory and anti-tumor effect of Ipomoea obscura (L) and its mode of action through the inhibition of pro inflammatory cytokines, nitric oxide and COX-2. Inflammation, 34(3), pp.171183.

Han, S.H., Kim, Y.G., Lee, S.H., Park, C.B., Han, S.W., Jang, H.J., Lee, H.J., Park, S.C., Kim, H.S., Lee, Y.S. and Kwon, D.Y., 2010. Anti inflammatory Activity of Codium fragile in Macrophages Induced by Peptidoglycan. Natural Product Sciences, 16(3), pp.153-158.

Han, S.R., Noh, M.Y., Lee, J.H. and Oh, T.J., 2015. Evaluation of antioxidant and antimicrobial activities of solvent extracts from Coriolus versicolor. Journal of the Korean Society of Food Science and Nutrition, 44(12), pp.1793-1798.

Heo, J.C., Woo, S.U., Kweon, M., Park, J.Y., Lee, H.K., Son, M., Rho, J.R. and Lee, S.H., 
2008. Aqueous extract of the Helianthus annuus seed alleviates asthmatic symptoms in vivo. International journal of molecular medicine, 21(1), pp.57-61.

Heurich A, Hofmann-Winkler H, Gierer S, Liepold T, Jahn O (2014). TMPRSS2 and ADAM17 cleave ACE2 differentially and only proteolysis by TMPRSS2 augments entry driven by the severe acute respiratory syndrome coronavirus spike protein. Journal of Virology 88 (2): 12931307. doi: 10.1128/JVI.02202-13

Ho, T.Y., Wu, S.L., Chen, J.C., Li, C.C. and Hsiang, C.Y., 2007. Emodin blocks the SARS coronavirus spike protein and angiotensin-converting enzyme 2 interaction. Antiviral research, 74(2), pp.92101.

Ho, T.Y., Wu, S.L., Chen, J.C., Li, C.C. and Hsiang, C.Y., 2007. Emodin blocks the SARS coronavirus spike protein and angiotensin-converting enzyme 2 interaction. Antiviral research, 74(2), pp.92101.

Ho, Y.L. and Chang, Y.S., 2002. Studies on the antinociceptive, anti-inflammatory and antipyretic effects of Isatis indigotica root. Phytomedicine, 9(5), pp.419-424.

Horby, P., Lim, W.S., Emberson, J.R., Mafham, M., Bell, J.L., Linsell, L., Staplin, N., Brightling, C., Ustianowski, A., Elmahi, E. and Prudon, B., 2020. Dexamethasone in Hospitalized Patients with Covid-19Preliminary Report. The New England journal of medicine. NEJMoa2021436. doi: 10.1056/NEJMoa2021436. [Online ahead of print.]

Hosseinzadeh, H., Ramezani, M., Shafaei, H. and Taghiabadi, E., 2013. Anticonvulsant effect of Berberis integerrima L. root extracts in mice. Journal of Acupuncture and Meridian Studies, 6(1), pp.12-17.

Hosseinzadeh, S., Jafarikukhdan, A., Hosseini, A. and Armand, R., 2015. The application of medicinal plants in traditional and modern medicine: a review of Thymus vulgaris. International Journal of Clinical Medicine, 6(09), p.635.

Hsu, C.H., Hwang, K.C., Chao, C.L., Chang, S.G., Ho, M.S. and Chou, P., 2006. Can herbal medicine assist against avian flu? Learning from the experience of using supplementary treatment with Chinese medicine on SARS or SARS-like infectious disease in 2003. Journal of Alternative \& Complementary Medicine, 12(6), pp.505-506.

Hsu, H.F., Hsiao, P.C., Kuo, T.C., Chiang, S.T., Chen, S.L., Chiou, S.J., Ling, X.H., Liang, M.T., Cheng, W.Y. and Houng, J.Y., 2016. Antioxidant and anti-inflammatory activities of Lonicera japonica Thunb. var. sempervillosa Hayata flower bud extracts prepared by water, ethanol and supercritical fluid extraction techniques. Industrial Crops and Products, 89, pp.543549.

Huang, W.C., Liu, C.Y., Shen, S.C., Chen, L.C., Yeh, K.W., Liu, S.H. and Liou, C.J., 2019. Protective effects of licochalcone A improve airway hyper-responsiveness and oxidative stress in a mouse model of asthma. Cells, 8(6), p.617.

Huang, W.H., Lee, A.R. and Yang, C.H., 2006. Antioxidative and anti-inflammatory activities of polyhydroxyflavonoids of Scutellaria baicalensis GEORGI. Bioscience, biotechnology, and biochemistry, 70(10), pp.2371-2380.

Hueza, I.M., Gotardo, A.T., da Silva Mattos, M.I. and Górniak, S.L., 2019 . Immunomodulatory effect of Cynara scolymus (artichoke) in rats. Phytotherapy Research,33(1), pp.167-173.

Ibrahim, S.R., Mohamed, G.A., Khedr, A.I. and Aljaeid, B.M., 2017. Anti-oxidant and antiinflammatory cyclic diarylheptanoids from Alnus japonica stem bark. Iranian journal of pharmacentical research: IJPR, 16(Suppl), p.83.

Idrees, M., Khan, S., Memon, N.H. and Zhang, Z., 2020. Effect of the Phytochemical Agents Against the SARS-CoV and Some of them Selected for Application to COVID-19: A Mini Review. Current Pharmaceutical Biotechnology. DOI:10.2174/138920102166620070320 1458 PMID: 32619167

Ip, S.P., Tse, A.S.M., Poon, M.K.T., Ko, K.M. and Ma, C.Y., 1997. Antioxidant activities of Polygonum multiflorum Thunb., in vivo 
and in vitro. Phytotherapy Research, 11(1), pp.42-44.

Jaiarj, P., Khoohaswan, P., Wongkrajang, Y., Peungvicha, P., Suriyawong, P., Saraya, M.S. and Ruangsomboon, O., 1999. Anticough and antimicrobial activities of Psidium guajava Linn. leaf extract. Journal of Ethnopharmacology, 67(2), pp.203-212.

Jain, V. and Yuan, J.M., 2020. Predictive symptoms and comorbidities for severe COVID-19 and intensive care unit admission: a systematic review and meta-analysis. InternationalJournal of Public Health, p.1.

Jeba, C.R., Vaidyanathan, R. and Rameshkumar, G., 2011. Immunomodulatory activity of aqueous extract of Ocimum sanctum in rat. Int J Pharm Biomed Res, 2(1), pp.33-8.

Jeon, H.S., Lee, Y.S. and Kim, N.W., 2009. The antioxidative activities of Torreya nucifera seed extracts. Journal of the Korean Society of Food Science and Nutrition, 38(1), pp.1-8.

Jiang, S., Hillyer, C. and Du, L., 2020. Neutralizing antibodies against SARS-CoV-2 and other human coronaviruses. Trends in immunology, 41(5), pp. 355-359

Jiménez-López, J., Ruiz-Medina, A., OrtegaBarrales, P. and Llorent-Martínez, E.J., 2017. Rosa rubiginosa and Fraxinus oxycarpa herbal teas: characterization of phytochemical profiles by liquid chromatography-mass spectrometry, and evaluation of the antioxidant activity. New Journal of Chemistry, 41(15), pp.7681-7688.

Jin, K.S., Oh, Y.N., Lee, J.Y., Son, B.Y., Choi, W., Lee, E.W., Kwon, H.J. and Kim, B.W., 2013. Anti-oxidative and antiinflammatory activities of seven medicinal herbs including Tetrapanax papyriferus and Piper longum Linne. Microbiology and Biotechnology Letters, 41(2), pp.253-262.

Jo, N.Y. and Kim, K.T., 2019. Antioxidant Activity and Anti-inflammatory Effect of Extracts from Paulownia tomentosa in LPSstimulated RAW264. 7 macrophage cells. Journal of Korean Medicine, 40(4), pp.72-83.

Joshi, K., Awte, S., Bhatnagar, P., Walunj, S., Gupta, R., Joshi, S., Sabharwal, S., Bani, S. and Padalkar, A.S., 2010. Cinnamomum zeylanicum extract inhibits proinflammatory cytokine TNF: in vitro and in vivo studies. Research In Pharmacentical Biotechnology, 2(2), pp.014021.

Joshi, R.K., 2013. Chemical composition, in vitro antimicrobial and antioxidant activities of the essential oils of Ocimum gratissimum, O. sanctum and their major constituents. Indian journal of pharmaceutical sciences, 75(4), p.457.

Jung, H.S., Kim, M.H., Gwak, N.G., Im, Y.S., Lee, K.Y., Sohn, Y., Choi, H. and Yang, W.M., 2012. Antiallergic effects of Scutellaria baicalensis on inflammation in vivo and in vitro. Journal of ethnopharmacology, 141(1), pp.345-349.

Kalikar, M.V., Thawani, V.R., Varadpande, U.K., Sontakke, S.D., Singh, R.P. and Khiyani, R.K., 2008. Immunomodulatory effect of Tinospora cordifolia extract in human immuno-deficiency virus positive patients. Indian journal of pharmacology, 40(3), p.107.

Kamal, A.M., Abdelhady, M.I., Elmorsy, E.M., Mady, M.S. and Abdelkhalik, S.M., 2012. Phytochemical and biological investigation of leaf extracts of Podocarpus gracilior and Ruprechtia polystachya resulted in isolation of novel polyphenolic compound. Life Science Journal,9(4), pp.1126-35.

Kamei, J., Nakamura, R., Ichiki, H. and Kubo, M., 2003. Antitussive principles of Glycyrrhizae radix, a main component of the Kampo preparations Bakumondo-to (Mai-men-dong-tang). European journal of pharmacology, 469(1-3), pp.159-163.

Kan, A. and Kartal, M., 2009. In vitro antiviral activities under cytotoxic doses against herpes simples type- 1 and parainfluensa-3 viruses of Cicer arietinum L.(Chickpea). African Journal of Pharmacy and Pharmacology, 3(12), pp.627-631.

Karakurt, S., Semiz, A., Celik, G., Gencler-Ozkan, A.M., Sen, A. and Adali, O., 2016. Contribution of ellagic acid on the antioxidant potential of medicinal plant Epilobium hirsutum. Nutrition and cancer, 68(1), pp.173-183.

Karthikeyan, R., Koushik, O.S. and Babu, P.S., 2011. Anti Pyretic Effect of Methanolic 
Extract of Strychnos colubrina L. Bark by Brewer's Yeast Induced Pyrexia in Albino Rats. Journal of Pharma and Biosciences, 2(2), pp.501-508.

Kerdudo, A., Njoh Ellong, E., Gonnot, V., Boyer, L., Michel, T., Adenet, S., Rochefort, K. and Fernandez, X., 2016. Essential oil composition and antimicrobial activity of Hyptis atrorubens Poit. from Martinique (FWI). Journal of EssEntial oil rEsEarch, 28(5), pp.436-444.

Kesharwani, A., Polachira, S.K., Nair, R., Agarwal, A., Mishra, N.N. and Gupta, S.K., 2017. Anti-HSV-2 activity of Terminalia chebula Retz extract and its constituents, chebulagic and chebulinic acids. BMC complementary and alternative medicine, 17(1), p.110.

Khaerunnisa, S., Kurniawan, H., Awaluddin, R., Suhartati, S. and Soetjipto, S., 2020. Potential inhibitor of COVID-19 main protease (Mpro) from several medicinal plant compounds by molecular docking study. Prepr. doi10, 20944, pp.1-14.

Khan, H.M., Raza, S.M., Anjum, A.A., Ali, M.A. and Akbar, H., 2019. Antiviral, embryo toxic and cytotoxic activities of Astragalus membranaceus root extracts. Pakistan journal of pharmacentical sciences, 32(1).

Kim, D.E., Min, J.S., Jang, M.S., Lee, J.Y., Shin, Y.S., Park, C.M., Song, J.H., Kim, H.R., Kim, S., Jin, Y.H. and Kwon, S., 2019. Natural bisbenzylisoquinoline alkaloids-tetrandrine, fangchinoline, and cepharanthine, inhibit human coronavirus OC43 infection of MRC-5 human lung cells. Biomolecules, 9(11), p.696.

Kim, D.W., Seo, K.H., Curtis-Long, M.J., Oh, K.Y., Oh, J.W., Cho, J.K., Lee, K.H. and Park, K.H., 2014. Phenolic phytochemical displaying SARS-CoV papain-like protease inhibition from the seeds of Psoralea corylifolia. Journal of ensyme inbibition and medicinal chemistry, 29(1), pp.59-63.

Kim, H.J., Lee, J.S., Yu, Y.G., Park, H. and Lee, Y.S., 2001. Isolation of HIV gp-41 Binding Components from the Stem of Fraxinus sieboldiana. In Proceedings of the PSK Conference (pp. 106-3). The Pharmaceutical
Society of Korea.

Kim, P.J., Yun, H.J., Heo, S.K., Kim, K., Kim, D.W., Kim, J.E. and Park, S.D., 2009. Antiinflammatory effect of Bodusan. The Korea Journal of Herbology, 24(2), pp.49-56.

Kim, S.H., Park, J.G., Hong, Y.D., Kim, E., Baik, K.S., Yoon, D.H., Kim, S., Lee, M.N., Rho, H.S., Shin, S.S. and Cho, J.Y., 2016. Src/Syk/IRAK1-targeted antiinflammatory action of Torreya nucifera butanol fraction in lipopolysaccharideactivated RAW264. 7 cells. Journal of ethnopharmacology, 188, pp.167-176.

Kong, Y.H., Lee, Y.C. and Choi, S.Y., 2009. Neuroprotective and anti-inflammatory effects of phenolic compounds in Panax ginseng CA Meyer. Journal of Ginseng Research, 33(2), pp.111-114.

Kongkathip, B., Kongkathip, N., Sunthitikawinsakul, A., Napaswat, C. and Yoosook, C., 2005. Anti-HIV-1 constituents from Clausena excavata: Part II. carbazoles and a pyranocoumarin. Phytotherapy Research: An International Journal Devoted to Pharmacological and Toxicological Evaluation of Natural Product Derivatives, 19(8), pp.728-731.

Kou, X., Gao, J., Xue, Z., Zhang, Z., Wang, H. and Wang, X., 2013. Purification and identification of antioxidant peptides from chickpea (Cicer arietinum L.) albumin hydrolysates. LWT-Food Science and Technology, 50(2), pp.591-598.

Koubaa, M., Driss, D., Bouaziz, F., Ghorbel, R.E. and Chaabouni, S.E., 2015. Antioxidant and antimicrobial activities of solvent extract obtained from rocket (Eruca sativa L.) flowers. Free Radicals \& Antioxidants, 5(1).

Koz, F.F.Y., Yavasoglu, N.U.K. and Demirel, Z., 2009. Antioxidant and antimicrobial activities of Codium fragile (Suringar) Hariot (Chlorophyta) essential oil and extracts. Asian Journal of Chemistry, 21(2), p.1197.

Krifa, M., Mustapha, N., Ghedira, Z., Ghedira, K., Pizzi, A. and Chekir-Ghedira, L., 2015. Limoniastrum guyonianum methanol extract induces immunomodulatory and anti-inflammatory effects by activating cellular anti-oxidant activity. Drug and 
chemical toxicology, 38(1), pp.84-91.

Kuttan, R., Bhanumathy, P., Nirmala, K. and George, M.C., 1985. Potential anticancer activity of turmeric (Curcuma longa). Cancerletters, 29(2), pp.197-202.

Lajter, I., San-Po, P., Vasas, A., Forgó, P., Hohmann, J. and Bauer, R., 2014. Antiinflammatory activity of Onopordum acanthium extracts and isolated compounds. Planta Medica, 80(16), p.P1L155.

Lalita, B., 1994. In vitro studies on the effect of glycyrrhizin from Indian Glycyrrhiza glabra Linn on some RNA and DNA viruses. Indian Journal of Pharmacology, 26(3), p.194.

Lau, K.M., Lee, K.M., Koon, C.M., Cheung, C.S.F., Lau, C.P., Ho, H.M., Lee, M.Y.H., Au, S.W.N., Cheng, C.H.K., Bik-San Lau, C. and Tsui, S.K.W., 2008. Immunomodulatory and anti-SARS activities of Houttuynia cordata. Journal of Ethnopharmacology, 118(1), pp.79-85.

Lau, T.F., Leung, P.C., Wong, E.L.Y., Fong, C., Cheng, K.F., Zhang, S.C., Lam, C.W.K., Wong, V., Choy, K.M. and Ko, W.M., 2005. Using herbal medicine as a means of prevention experience during the SARS crisis. The American Journal of Chinese Medicine, 33(03), pp.345-356.

Lee, D.Y., Noh, H.J., Choi, J., Lee, K.H., Lee, M.H., Lee, J.H., Hong, Y., Lee, S.E., Kim, S.Y. and Kim, G.S., 2013. Anti-inflammatory cycloartane-type saponins of Astragalus membranaceus. Molecules, 18(4), pp.37253732.

Lee, H.J., Choi, T.W., Kim, H.J., Nam, D., Jung, S.H., Lee, E.H., Lee, H.J., Shin, E.M., Jang, H.J., Ahn, K.S. and Shim, B.S., 2010. AntiInflammatory Activity of Angelica keiskei Through Suppression of MitogenActivated Protein Kinases and Nuclear Factor- $x$ B Activation Pathways. Journal of medicinal food, 13(3), pp.691-699.

Lee, J.Y., Ko, S.H., Lee, Y.J., Lee, S.Y., Park, H.J., Shin, T.Y. and Jeon, H., 2010. Antiinflammatory Effect of $\mathrm{MeOH}$ Extract of Cibotium barometz in IFN-\$ $\$$ gamma $\$$ and LPS-stimulated Mouse Peritoneal Macrophage. Korean Journal of Pharmacognosy, 41(2), pp.108-114.
Lee, T.Y., Mai, L.M., Wang, G.J., Chiu, J.H., Lin, Y.L. and Lin, H.C., 2003. Protective mechanism of salvia miltiorrhiza on carbon tetrachloride-induced acute hepatotoxicity in rats. Journal of pharmacological sciences, 91(3), pp.202-210.

Li, T. and Peng, T., 2013. Traditional Chinese herbal medicine as a source of molecules with antiviral activity. Antiviral research, 97(1), pp.1-9.

Li, X.M. and Yang, P.L., 2018. Research progress of Sonchus species. International journal of foodproperties, 21(1), pp.147-157.

Lim, J.S., Hahn, D., Gu, M.J., Oh, J., Lee, J.S. and Kim, J.S., 2019. Anti-inflammatory and antioxidant effects of 2, 7-dihydroxy-4, 6dimethoxy phenanthrene isolated from Dioscorea batatas Decne. Applied Biological Chemistry, 62(1), pp.1-9.

Lin, S., Zhang, Y., Liu, M., Yang, S., Gan, M., Zi, J., Song, W., Fan, X., Wang, S., Liu, Y. and Yang, Y., 2010. Abietane and C20norabietane diterpenes from the stem bark of Fraxinus sieboldiana and their biological activities. Journal of natural products, 73(11), pp.1914-1921.

Linde, K. and Jonas, W.B., 1999. Evaluating complementary and alternative medicine: the balance of rigor and relevance. Essentials of Complementary and Alternative Medicine. Philadelphia: Lippincott,pp.57-71.

Liu, H., Ye, F., Sun, Q., Liang, H., Li, C., Lu, R., Huang, B., Tan, W. and Lai, L., 2020. Scutellaria baicalensis extract and baicalein inhibit replication of SARS$\mathrm{CoV}-2$ and its $3 \mathrm{C}$-like protease in vitro. $B i \circ \mathrm{R} \times i v \quad$ D O I : 10.1101/2020.04.10.035824 PPR: PPR150387 Preprint

Liu, M., Yu, Q., Yi, Y., Xiao, H., Putra, D.F., Ke, K., Zhang, Q. and Li, P., 2020. Antiviral activities of Lonicera japonica Thunb. Components against grouper iridovirus in vitro and in vivo. Aquaculture, 519, p. 734882 .

Liu, Y.T., Chen, H.W., Lii, C.K., Jhuang, J.H., Huang, C.S., Li, M.L. and Yao, H.T., 2020. A Diterpenoid, 14-Deoxy-11, 12 Didehydroandrographolide, in Andrographis paniculata Reduces 
Steatohepatitis and Liver Injury in Mice Fed a High-Fat and High-Cholesterol Diet. Nutrients, 12(2), p.523.

López-Alcalde, J., Yan, Y., Witt, C.M. and Barth, J., 2020. Current state of research about Chinese herbal medicines (CHM) for the treatment of coronavirus disease 2019 (COVID-19): a scoping review. The Journal of Alternative and Complementary Medicine, 26(7), pp.557-570.

Lu, H., 2020. Drug treatment options for the 2019-new coronavirus (2019-nCoV). Bioscience trends, 14(1), pp.69-71.

Lu, Y., Shipton, F.N., Khoo, T.J. and Wiart, C., 2014. Antioxidant activity determination of citronellal and crude extracts of Cymbopogon citratus by 3 different methods. Pharmacology \& Pharmacy, 2014.

Luo, E., Zhang, D., Luo, H., Liu, B., Zhao, K., Zhao, Y., Bian, Y. and Wang, Y., 2020 Treatment efficacy analysis of traditional Chinese medicine for novel coronavirus pneumonia (COVID-19): an empirical study from Wuhan, Hubei Province, China. Chinese Medicine, 15, pp.1-13.

Luo, H., Tang, Q.L., Shang, Y.X., Liang, S.B., Yang, M., Robinson, N. and Liu, J.P., 2020'. Can Chinese medicine be used for prevention of corona virus disease 2019 (COVID19)? A review of historical classics, research evidence and current prevention programs. Chinese journal of integrative medicine, pp.1-8.

Luo, L., Jiang, J., Wang, C., Fitzgerald, M., Hu, W., Zhou, Y., Zhang, H. and Chen, S., $2020^{\circ}$. Analysis on herbal medicines utilized for treatment of COVID-19. Acta Pharmacentica Sinica B, 10 (7) 2020,p.1921204

Majeed, M.F., Numan, I.T. and Noori, M., 2015. Study the anti-inflammatory activity of artichoke (cynara scolymus) different extracts in experimentel models of acute inflammation in rats. Pharmacie Globale, 6(4), p.1.

Malaník, M., Treml, J., Leláková, V., Nykodýmová, D., Oravec, M., Marek, J. and Šmejkal, K., 2020. Anti-inflammatory and antioxidant properties of chemical constituents of Broussonetia papyrifera. Bioorganic Chemistry, 104, p.104298.
Mani, J.S., Johnson, J.B., Steel, J.C., Broszczak, D.A., Neilsen, P.M., Walsh, K.B. and Naiker, M., 2020. Natural product-derived phytochemicals as potential agents against coronaviruses: a review. Virus Research, p.197989.

Mbah, J.A., Tane, P., Ngadjui, B.T., Connolly, J.D., Okunji, C.C., Iwu, M.M. and Schuster, B.M., 2004. Antiplasmodial agents from the leaves of Glossocalyx brevipes. Planta medica, 70(05), pp.437-440.

Meng, L., Guo, Q., Liu, Y., Chen, M., Li, Y., Jiang, J. and Shi, J., 2017. Indole alkaloid sulfonic acids from an aqueous extract of Isatis indigotica roots and their antiviral activity. Acta pharmacentica sinica B, 7(3), pp.334341.

Michaelis, M., Doerr, H.W. and Cinatl Jr, J., 2011. Investigation of the influence of EPs $\AA$ 7630 , a herbal drug preparation $\mathrm{f}$ gonium sidoides, on replication of a broad panel of respiratory viruses. Phytomedicine, 18(5), pp.384-386.

Milán-Noris, A.K., Gutiérrez-Uribe, J.A., Santacruz, A., Serna-Saldívar, S.O. and Martínez-Villaluenga, C., 2018. Peptides and isoflavones in gastrointestinal digests contribute to the anti-inflammatory potential of cooked or germinated desi and kabuli chickpea (Cicer arietinum L.). Food chemistry, 268, pp.66-76.

Mittal, A., Manjunath, K., Ranjan, R.K., Kaushik, S., Kumar, S. and Verma, V., 2020. COVID-19 pandemic: Insights into structure, function, and hACE2 receptor recognition by SARS-CoV-2. PLoS pathogens, 16(8), p.e1008762

Moghtader, M., 2013. In vitro antifungal effects of Fumaria vaillantii Loisel essential oil on Aspergillus flavus. Journal of Yeast and Fungal Research, 4(2), pp.21-25.

Mohamed, A.A., Khalil, A.A. and El-Beltagi, H.E., 2010. Antioxidant and antimicrobial properties of kaff maryam (Anastatica hierochuntica) and doum palm (Hyphaene thebaica). Grasas Y Aceites, 61(1), pp.67-75.

Muhammad, N., Lal Shrestha, R., Adhikari, A., Wadood, A., Khan, H., Khan, A.Z., Maione, F., Mascolo, N. and De Feo, V., 2015. First evidence of the analgesic 
activity of govaniadine, an alkaloid isolated from Corydalis govaniana Wall. Natural product research, 29(5), pp.430-437.

Mwangi, E.S.K., Keriko, J.M., Machocho, A.K., Wanyonyi, A.W., Malebo, H.M., Chhabra, S.C. and Tarus, P.K., 2010. Antiprotozoal activity and cytotoxicity of metabolites from leaves of Teclea trichocarpa. Journal of Medicinal Plants Research, 4(9), pp.726731.

Nagalingam, M., Rajeshkumar, S., Panneerselvam, A. and Lakshmi, T., 2019. Antibacterial and Antifungal potential of acetone, ethanol and methanolic extract of marine red algae Gelidium amansii. International Journal of Research in Pharmaceutical Sciences, 10(2), pp.1013-1018.

Nasr, F.A., Noman, O.M., Mothana, R.A., Alqahtani, A.S. and Al-Mishari, A.A., 2020. Cytotoxic, antimicrobial and antioxidant activities and phytochemical analysis of Artemisia judaica and A. sieberi in Saudi Arabia. African Journal of Pharmacy and Pharmacology, 14(8), pp.278284.

Ndjateu, F.S., Tsafack, R.B., Nganou, B.K., Awouafack, M.D., Wabo, H.K., Tene, M., Tane, P. and Eloff, J.N., 2014. Antimicrobial and antioxidant activities of extracts and ten compounds from three Cameroonian medicinal plants: Dissotis perkinsiae (Melastomaceae), Adenocarpus mannii (Fabaceae) and Barteria fistulosa (Passifloraceae). South African Journal of Botany, 91, pp.37-42.

Neve, V., Bandivadekar, P., Patil, P. and Kutal, P., 2018. Evaluation of anti-inflammatory activity of Ethanolic extract of fruit of Psoralea Corylifolia Linn. Journal of Pharmacognosy and Phytochemistry 7(SP6), pp. 35-37.

NIH, 2020. National Institute of Health. COVID-19 Treatment guidelines. http:/www.nih.gov/corona virus. Accessed $15^{\text {th }}$ October, 2020.

Nkunya, M.H., Makangara, J.J. and Jonker, S.A., 2004. Prenylindoles from tanzanian Monodora and Isolona species. Natural product research, 18(3), pp.253-258.

Ohta, Y., Lee, J.B., Hayashi, K. and Hayashi, T., 2009. Isolation of sulfated galactan from
Codium fragile and its antiviral effect. Biological and Pharmaceutical Bulletin, 32(5), pp.892-898.

Oliveira, A.B.S., Dias Filho, B.P., Nakamura, C.V. and Ueda-Nakamura, T., 2009. Antiviral activity and mode of action of a peptide isolated from Helianthus annus. Planta Medica, 75(09), p.PF8.

Onyenekwe, P.C., Ajani, E.O., Ameh, D.A. and Gamaniel, K.S., 1999. Antihypertensive effect of roselle (Hibiscus sabdariffa) calyx infusion in spontaneously hypertensive rats and a comparison of its toxicity with that in Wistar rats. Cell Biochemistry and Function: Cellular biochemistry and its modulation by active agents ordisease, 17(3), pp.199-206.

Oomah, B.D., Corbé, A. and Balasubramanian, P., 2010. Antioxidant and anti-inflammatory activities of bean (Phaseolus vulgaris L.) hulls. Journal of Agricultural and Food Chemistry, 58(14), pp.8225-8230.

Osorio, A.A., Torres, D.F., Bedoya, L.M., Munoz, A., Alcami, J. and Bazzocchi, I.L., 2011. Anti-HIV activity of $\Delta 18$-oleane triterpenoids from Cassine xylocarpa. Planta Medica, 77(12), p.PG45.

Pan, X., Dong, L., Yang, N., Chen, D. and Peng, C., 2020. Potential drugs for the treatment of the novel coronavirus pneumonia (COVID-19) in China. Virus Research, p.198057.

Parizipour, M.G. and Shahriari, A.G., 2020. Investigation of Antiviral Potential of Licorice (Glycyrrhiza Glabra L.) Crude Extract against Tobacco Mosaic Virus. Journal of Animal and Plant Sciences, 30(1), pp.107-114.

Park, C.M. and Yoon, H.S., 2018. AntiInflammatory Effects of Gelidium amansii Ethanol Extract on Porphyromonas gingivalis Lipopolysacchari-de-Stimulated Human Gingival Fibroblasts through the Regulation of Nuclear Factor Kappa B/Activator Protein-1/MitogenActivated Protein Kinase Signaling Pathway. International Journal of Clinical Preventive Dentistry, 14(3), pp.197-202.

Park, J.Y., Yuk, H.J., Ryu, H.W., Lim, S.H., Kim, K.S., Park, K.H., Ryu, Y.B. and Lee, W.S., 
2017. Evaluation of polyphenols from Broussonetia papyrifera as coronavirus protease inhibitors. Journal of ensyme inbibition and medicinal chemistry, 32(1), pp.504-512.

Park, S.Y., Jin, M.L., Kang, N.J., Park, G. and Choi, Y.W., 2017. Anti-inflammatory effects of novel polygonum multiflorum compound via inhibiting NF- $x \mathrm{~B} / \mathrm{MAPK}$ and upregulating the Nrf2 pathways in LPSstimulated microglia. Neuroscience Letters, 651, pp.43-51.

Pasdaran, A. and Hamedi, A., 2017. The genus Scrophularia: a source of iridoids and terpenoids with a diverse biological activity. Pharmacentical biology, 55(1), pp.2211-2233.

Patel, S. and Patel, V., 2019. Inhibitory effects of catechin isolated from Acacia catechu on ovalbumin induced allergic asthma model. Nutrition \& Food Science.

Patil, M.V.K., Kandhare, A.D. and Bhise, S.D., 2012. Anti-inflammatory effect of Daucus carota root on experimental colitis in rats. Int J Pharm Pharm Sci, 4(1), pp.337-343.

Paul, A., Das, S., Das, J., Samadder, A., Bishayee, K., Sadhukhan, R. and Khuda-Bukhsh, A.R., 2013. Diarylheptanoid-myricanone isolated from ethanolic extract of Myrica cerifera shows anticancer effects on HeLa and PC3 cell lines: signalling pathway and drug-DNA interaction. Journal of integrative medicine, 11(6), pp.405-415.

Peng, C., Perera, P.K., Li, Y.M., Fang, W.R., Liu, L.F. and Li, F.W., 2012. Anti-inflammatory effects of Clematis chinensis Osbeck extract (AR-6) may be associated with NF$x \mathrm{~B}, \mathrm{TNF}-\alpha$, and COX-2 in collageninduced arthritis in rat. Rheumatology international, 32(10), pp.3119-3125.

Petrolini, F.V.B., Lucarini, R., Souza, M.G.M.D., Pires, R.H., Cunha, W.R. and Martins, C.H.G., 2013. Evaluation of the antibacterial potential of Petroselinum crispum and Rosmarinus officinalis against bacteria that cause urinary tract infections. Brazilian Journal of Microbiology, 44(3), pp.829-834.

Petropoulos, S.A., Di Gioia, F., Polyzos, N. and Tzortzakis, N., 2020. Natural antioxidants, health effects and bioactive properties of wild Allium species. Current Pharmacentical Design, 26(16), pp.1816-1837.

Pithayanukul, P., Nithitanakool, S. and Bavovada, R., 2009. Hepatoprotective potential of extracts from seeds of Areca catechu and nutgalls of Quercus infectoria. Molecules, 14(12), pp.4987-5000.

Pongtuluran, O.B. and Rofaani, E., 2015. Antiviral and immunostimulant activities of Andrographis paniculata. HAYATI Journal of Biosciences, 22(2), pp.67-72.

Potere, N., Di Nisio, M., Cibelli, D., Scurti, R., Frattari, A., Porreca, E., Abbate, A. and Parruti, G., 2020. Interleukin-6 receptor blockade with subcutaneous tocilizumab in severe COVID-19 pneumonia and hyperinflammation: a case-control study. Annals of the Rheumatic Diseases. Published Online First: 09 July 2020. doi: 10.1136/annrheumdis-2020-218243.

Pulipati, S., Babu, P.S., Naveena, U., Parveen, S.R., Nausheen, S.S. and Sai, M.T.N., 2017. Determination of total phenolic, tannin, flavonoid contents and evaluation of antioxidant property of amaranthus tricolor (L). International Journal of Pharmacognosy and Phytochemical Research, 9(6), pp.814-19.

Rached, W., Zeghada, F.Z., Bennaceur, M., Barros, L., Calhelha, R.C., Heleno, S., Alves, M.J., Carvalho, A.M., Marouf, A. and Ferreira, I.C., 2018. Phytochemical analysis and assessment of antioxidant, antimicrobial, anti-inflammatory and cytotoxic properties of Tetraclinis articulata (Vahl) Masters leaves. Industrial Crops and Products, 112, pp.460-466.

Ramachandran, J., Arul, A.D. and Thilagar, S., 2019. Hepatoprotective and antioxidant activity of Ipomoea staphylina Linn. ClinicalPhytoscience, 5(1).

Ramezani, M., Nasri, S. and Yassa, N., 2009. Antinociceptive and anti-inflammatory effects of isolated fractions from Apium graveolens seeds in mice. Pharmacentical biology, 47(8), pp.740-743.

Rashid, M.A., Gustafson, K.R., Kashman, Y., Cardellina, J.H., McMahon, J.B. and Boyd, M.R., 1995. Anti-HIV alkaloids from Toddalia asiatica. Natural product letters, 
6(2), pp.153-156.

Rastogi, B., Tiwari, U., Dubey, A., Bawra, B., Nandini, D., Chauhan, N.S. and Saraf, D.K., 2009. Immunomodulating activity of Cleome gynandra. Pharmacologyonline, 2, pp.151-69.

Rastogi, S., Pandey, D.N. and Singh, R.H., 2020. COVID-19 Pandemic: A pragmatic plan for Ayurveda Intervention. Journal of Ayurveda and Integrative medicine. doi: 10.1016/j.jaim.2020.04.002

Ren, J.L., Zhang, A.H. and Wang, X.J., 2020. Traditional Chinese medicine for COVID-19 treatment. Pharmacological research, 155, p.104743.

Renda, G., Arzu, Ö.Z.E.L., Barut, B., Korkmaz, B. and Yayli, N., 2018. In vitro protection by Crataegus microphylla extracts against oxidative damage and enzyme inhibition effects. Turkish Journal of Pharmacentical Sciences, 15(1), p.77.

Risaliti, L., Kehagia, A., Daoultzi, E., Lazari, D., Bergonzi, M.C., Vergkizi-Nikolakaki, S., Hadjipavlou-Litina, D. and Bilia, A.R., 2019. Liposomes loaded with Salvia triloba and Rosmarinus officinalis essential oils: In vitro assessment of antioxidant, antiinflammatory and antibacterial activities. Journal of Drug Delivery Science and Technology, 51, pp.493498.

Robinson, 2020. Everything you need to know about the COVID-19 therapy trials. The Pharmaceutical Journal. https://www. pharmaceutical-journal.com/news-andanalysis/features/everything-you-needto-know-about-the-covid-19-therapytrials/20208126.article. Accessed 21 ${ }^{\text {st }}$ October, 2020.

Ryu, Y.B., Jeong, H.J., Kim, J.H., Kim, Y.M., Park, J.Y., Kim, D., Naguyen, T.T.H., Park, S.J., Chang, J.S., Park, K.H. and Rho, M.C., 2010. Biflavonoids from Torreya nucifera displaying SARS-CoV 3CLpro inhibition. Bioorganic \& medicinal chemistry, 18(22), pp.7940-7947.

Saleh, M.H., Rashedi, I. and Keating, A., 2017. Immunomodulatory properties of Coriolus versicolor: The role of polysaccharopeptide. Frontiers in immunology, 8, p.1087..
Salzberger, B., Glück, T. and Ehrenstein, B., 2020. Successful containment of COVID-19: the WHO-Report on the COVID-19 outbreak in China. Infection, 48(2): 151-153.

Samaee, H., Mohsenzadegan, M., Ala, S., Maroufi, S.S. and Moradimajd, P., 2020. Tocilizumab for treatment patients with COVID-19: recommended medication for novel disease. International Immunopharmacology, p.107018.

Samra, R.M., Soliman, A.F., Zaki, A.A., Hassan, M.A. and Zaghloul, A.M., 2020. Antiviral Components from Cleome droserifolia and Lotus creti-cus. Indian Journal of Science and Technology, 13(28), pp.2866-2875.

San Chang, J., Wang, K.C., Yeh, C.F., Shieh, D.E. and Chiang, L.C., 2013. Fresh ginger (Zingiber officinale) has anti-viral activity against human respiratory syncytial virus in human respiratory tract cell lines. Journal of ethnopharmacology, 145(1), pp.146-151.

Sanna, G., Madeddu, S., Serra, A., Collu, D., Efferth, T., Hakkim, F.L. and Rashan, L., 2019. Anti-poliovirus activity of Nerium oleander aqueous extract. Natural Product Research,pp.1-4.

Satyal, P., Shrestha, S. and Setzer, W.N., 2015. Composition and bioactivities of an (E)$\beta$-farnesene chemotype of chamomile (Matricaria chamomilla) essential oil from Nepal. Natural Product Communications, 10(8),p.1934578X1501000835.

Schinella, G.R., Tournier, H.A., Prieto, J.M., De Buschiazzo, P.M. and Rios, J.L., 2002. Antioxidant activity of anti-inflammatory plant extracts. Life sciences, 70(9), pp.10231033.

Schlesinger, N., Firestein, B.L. and Brunetti, L., 2020. Colchicine in COVID-19: an Old Drug, New Use. Current Pharmacology Reports, 6(4), pp.137-145.

Seddighfar, M., Mirghazanfari, S.M. and Dadpay, M., 2020. Analgesic and antiinflammatory properties of hydroalcoholic extracts of Malva sylvestris, Carum carvi or Medicago sativa, and their combination in a rat model. Journal of Integrative Medicine, 18(2), pp.181188.

Sen, T., Nasralla, H.S. and Chaudhuri, A.N., 1995. 
Studies on the antiinflammatory and related pharmacological activities of Psidium guajava: a preliminary report. Phytotherapy Research, 9(2), pp.118-122.

Shang, X.F., Zhao, Z.M., Li, J.C., Yang, G.Z., Liu, Y.Q., Dai, L.X., Zhang, Z.J., Yang, Z.G., Miao, X.L., Yang, C.J. and Zhang, J.Y., 2019. Insecticidal and antifungal activities of Rheum palmatum L. anthraquinones and structurally related compounds. Industrial Crops and Products, 137, pp.508520.

Sharma, S., Dangi, M.S., Wadhwa, S., Daniel, V. and Tiwari, A., 2010. Antibacterial activity of Cassia tora leaves. Int J Pharm \& Biol Arch, 1(1), pp.84-6.

Shebaby, W.N., 2014. Evaluation of Antioxidant, Anticancer and Immunomodulatory Activities of Wild Carrot (Daucus carota ssp. carota) Oil and its Fractions (Doctoral dissertation, University of Surrey (United Kingdom)).

Sheeja, K., Shihab, P.K. and Kuttan, G., 2006. Antioxidant and anti-inflammatory activities of the plant Andrographis paniculata Nees. Immunopharmacology and immunotoxicology, 28(1), pp.129-140.

Shen, L., Niu, J., Wang, C., Huang, B., Wang, W., Zhu, N., Deng, Y., Wang, H., Ye, F., Cen, S. and Tan, W., 2019. High-throughput screening and identification of potent broad-spectrum inhibitors of coronaviruses. Journal of virology, 93(12).

Shi, M., Zhang, Z. and Yang, Y., 2013. Antioxidant and immunoregulatory activity of Ganoderma lucidum polysaccharide (GLP). Carbohydrate Polymers, 95(1), pp.200-206.

Shin, E.M., Zhou, H.Y., Guo, L.Y., Kim, J.A., Lee, S.H., Merfort, I., Kang, S.S., Kim, H.S., Kim, S. and Kim, Y.S., 2008. Antiinflammatory effects of glycyrol isolated from Glycyrrhiza uralensis in LPSstimulated RAW264. 7 macrophages. International immunopharmacology, 8(11), pp.1524-1532.

Shrestha, R.L. and Adhikari, A., 2017. Antioxidant Constituents from Corydalis govaniana Wall and C. casimiriana Duthie and Prain ex Prain. Journal of Pharmacognosy and Phytochemistry, 6(5), pp.568-570.

Siddiqui, M.Z., 2011. Boswellia serrata, a potential antiinflammatory agent: an overview. Indian journal of pharmaceutical sciences, 73(3), p.255.

Signer, J., Jonsdottir, H.R., Albrich, W.C., Strasser, M., Züst, R., Ryter, S., AckermannGäumann, R., Lenz, N., Siegrist, D., Suter, A. and Schoop, R., 2020. In vitro antiviral activity of Echinaforce ${ }^{\circledR}$, an Echinacea purpurea preparation, against common cold coronavirus 229E and highly pathogenic MERS-CoV and SARS-CoV.

Simmons G, Zmora P, Gierer S, Heurich A, Pohlmann S (2013).Proteolytic activation of the SARS-coronavirus spike protein: cutting enzymes at the cutting edge of antiviral research. Antiviral Research 100 ( 3 ) : $605-614 . \quad \mathrm{d}$ o i : 10.1016/j.antiviral.2013.09.028

Slighoua, M., Mahdi, I., Di Cristo, F., Amaghnouje, A., Grafov, A., Boucetta, N., Bari, A. and Bousta, D., 2020. Assessment of in vivo estrogenic and anti-inflammatory activities of the hydro-ethanolic extract and polyphenolic fraction of parsley (Petroselinum sativum Hoffm.). Journal of Ethnopharmacology, 265, p.113290.

Sofowora EA. Medicinal Plants and Traditional Medicine in Africa. 2nd ed. Ibadan, Nigeria: John Wiley and Sons Ltd, Spectrum Books; 1993. pp. 55-62

Somova, L.I., Shode, F.O., Ramnanan, P. and Nadar, A., 2003. Antihypertensive, antiatherosclerotic and antioxidant activity of triterpenoids isolated from Olea europaea, subspecies africana leaves. Journal of ethnopharmacology, 84(2-3), pp.299-305.

Soumaya, B., Yosra, E., Rim, B.M., Sarra, D., Sawsen, S., Sarra, B., Kamel, M., Wissem, A.W., Isoda, H. and Wided, M.K., 2020. Preliminary phytochemical analysis, antioxidant, anti-inflammatory and anticancer activities of two Tunisian Ephedra species: Ephedra alata and Ephedra fragilis. South African Journal of Botany, 135, pp.421-428.

Stanisavljević, I.T., Stojičević, S.S., Veličković, D.T., Lazić, M.L. and Veljković, V.B., 2008. Screening the antioxidant and 
antimicrobial properties of the extracts from plantain (Plantago major L.) leaves. Separation Science and Technology, 43(14), pp.3652-3662.

Stohs, S.J. and Bagchi, D., 2015. Antioxidant, anti-inflammatory, and chemoprotective properties of Acacia catechu heartwood extracts. Phytotherapy Research, 29(6), pp.818-824.

Sudira, I.W. and Merdana, I.M., 2017. Extract Ashitaba (Angelica Keiskei) Improving The Immune Response Il-2, Ifn-Tbalb/C Mice Vaccinated With Rabies Vaccine. Journal of Veterinary and Animal Sciences, $1(2)$, p. 50-54.

Suryanarayana, L. and Banavath, D., 2020. A Review on Identification of Antiviral Potential Medicinal Plant Compounds against COVID-19. International Journal of Research in Engineering, Science and Management, 3(3), pp.675-679.

Tadic, V.M., Dobric, S., Markovic, G.M., Đorđevic, S.M., Arsic, I.A., Menkovic, N.R. and Stevic, T., 2008. Antiinflammatory, gastroprotective, freeradical-scavenging, and antimicrobial activities of hawthorn berries ethanol extract. Journal of agricultural and food chemistry, 56(17), pp.7700-7709.

Takeda, Y., Murata, T., Jamsransuren, D., Suganuma, K., Kazami, Y., Batkhuu, J., Badral, D. and Ogawa, H., 2020. Saxifraga spinulosa-Derived Components Rapidly Inactivate Multiple Viruses Including SARS-CoV-2. Viruses, 12(7), p.699.

Tchoumbougnang, F., Zollo, P.A., Dagne, E. and Mekonnen, Y., 2005. In vivo antimalarial activity of essential oils from Cymbopogon citratus and Ocimum gratissimum on mice infected with Plasmodium berghei. Planta medica, 71(01), pp.20-23.

Tepe, A.S. and Ozaslan, M., 2020. Anti-alzheimer, anti-diabetic, skin-whitening, and antioxidant activities of the essential oil of Cinnamomum zeylanicum. Industrial Crops and Products, 145, p.112069.

Tian, S., Hu, N., Lou, J., Chen, K., Kang, X., Xiang, Z., Chen, H., Wang, D., Liu, N., Liu, D. and Chen, G., 2020. Characteristics of COVID-19 infection in Beijing. Journal of
Infection, 80(4), pp. 401-406

Todkar, S.S., Chavan, V.V. and Kulkarni, A.S., 2010. Screening of secondary metabolites and antibacterial activity of Acacia concinna. Research journal of microbiology, 5(10), pp.974-979.

Todorov, D., Hinkov, A., Shishkova, K. and Shishkov, S., 2014. Antiviral potential of Bulgarian medicinal plants. Phytochemistry Reviews, 13(2), pp.525-538.

Torky, Z.A., 2013. Antiviral activity of polyphenols extracts from Daucus carota against Herpes simplex virus type 1. TOJSAT: The Online J Sci Technol 2013; 3 (1):20,32.

Tsai, T.H., Tsai, P.J. and Ho, S.C., 2005. Antioxidant and anti-inflammatory activities of several commonly used spices. Journal of food science, 70(1), pp.C93C97.

Tsai, Y.C., Lee, C.L., Yen, H.R., Chang, Y.S., Lin, Y.P., Huang, S.H. and Lin, C.W., 2020. Antiviral action of Tryptanthrin isolated from Strobilanthes cusia leaf against human coronavirus NL63. Biomolecules, 10(3), p.366.

Tung, N.H., Kwon, H.J., Kim, J.H., Ra, J.C., Ding, Y., Kim, J.A. and Kim, Y.H., 2010. Antiinfluenza diarylheptanoids from the bark of Alnus japonica. Bioorganic \& medicinal chemistry letters, 20(3), pp.1000-1003.

ul Haq, R., Wahab, A., Ayub, K., Mehmood, K., Sherkheli, M.A., Khan, R.A. and Raza, M., 2013. Antitussive efficacy and safety profile of ethyl acetate fraction of Terminalia chebula. ISRN pharmacology, 2013.

ul Qamar, M.T., Alqahtani, S.M., Alamri, M.A. and Chen, L.L., 2020. Structural basis of SARS-CoV-2 3CLpro and anti-COVID19 drug discovery from medicinal plants. Journal of pharmaceutical analysis, 10 (4), pp. 313-319

Ulasli, M., Gurses, S.A., Bayraktar, R., Yumrutas, O., Oztuzcu, S., Igci, M., Igci, Y.Z., Cakmak, E.A. and Arslan, A., 2014. The effects of Nigella sativa (Ns), Anthemis hyalina (Ah) and Citrus sinensis (Cs) extracts on the replication of coronavirus and the expression of TRP genes family. Molecular biology reports, 41(3), pp.1703- 
1711.

Upadhyay, S., Tripathi, P.K., Singh, M., Raghavendhar, S., Bhardwaj, M. and Patel, A.K., 2020. Evaluation of medicinal herbs as a potential therapeutic option against SARS-CoV-2 targeting its main protease. Phytotherapy Research. https://doi.org/10.1002/ptr.6802 (Online Version of Record before inclusion in an issue)

Uzma, M., Sunayana, N., Raghavendra, V.B., Madhu, C.S., Shanmuganathan, R. and Brindhadevi, K., 2020. Biogenic synthesis of gold nanoparticles using Commiphora wightii and their cytotoxic effects on breast cancer cell line (MCF-7). Process Biochemistry, 92, pp. 269-276

Vamvaka, E., Arcalis, E., Ramessar, K., Evans, A., O'Keefe, B.R., Shattock, R.J., Medina, V., Stöger, E., Christou, P. and Capell, T., 2016. Rice endosperm is cost-effective for the production of recombinant griffithsin with potent activity against HIV. Plant biotechnology journal, 14(6), pp.1427-1437.

Vellingiri, B., Jayaramayya, K., Iyer, M., Narayanasamy, A., Govindasamy, V., Giridharan, B., Ganesan, S., Venugopal, A., Venkatesan, D., Ganesan, H. and Rajagopalan, K., 2020. COVID-19: A promising cure for the global panic. Science of The TotalEnvironment, p.138277.

Venkatesan, J., Kim, S.K. and Shim, M.S., 2016. Antimicrobial, antioxidant, and anticancer activities of biosynthesized silver nanoparticles using marine algae Ecklonia cava. Nanomaterials, 6(12), p.235.

Vinaya, M., 2017. Bronchodilator activity of Ocimum sanctum Linn.(tulsi) in mild and moderate asthmatic patients in comparison with salbutamol: a singleblind cross-over study. International Journal of Basic \& Clinical Pharmacology, 6(3), p.511.

Vivek-Ananth, R.P., Rana, A., Rajan, N., Biswal, H.S. and Samal, A., 2020. In silico identification of potential natural product inhibitors of human proteases key to SARS-CoV-2 infection. arXiv preprint arXiv:2006.00652.

Walls, A.C., Park, Y.J., Tortorici, M.A., Wall, A., McGuire, A.T., Veesler, D., 2020. Structure function and antigenicity of the
SARS-CoV-2 spike glycoprotein. Cell, 181(2), pp. 281-292.e6

Wan, S., Xiang, Y., Fang, W., Zheng, Y., Li, B., Hu, Y., Lang, C., Huang, D., Sun, Q., Xiong, Y. and Huang, X., 2020. ${ }^{2}$. Clinical features and treatment of COVID-19 patients in northeast Chongqing. Journal of medical virology, pp. 797-806

Wan, Y., Shang, J., Graham, R., Baric, R.S. and Li, F., 2020' . Receptor recognition by the novel coronavirus from Wuhan: an analysis based on decade-long structural studies of SARS coronavirus. Journal of virology, 94(7).

Wen, C.C., Shyur, L.F., Jan, J.T., Liang, P.H., Kuo, C.J., Arulselvan, P., Wu, J.B., Kuo, S.C. and Yang, N.S., 2011. Traditional Chinese medicine herbal extracts of Cibotium barometz, Gentiana scabra, Dioscorea batatas, Cassia tora, and Taxillus chinensis inhibit SARS-CoV replication. Journal of traditional and complementary medicine, 1(1), pp.41-50.

West, B.J., Jensen, C.J., Palu, A.K., Deng, S. and Wasden, J.A., Tahitian Noni International Inc, 2011. Acai and iridoid based formulations. U.S. Patent Application 13/032,550.

WHO (2013). World Health Organization traditional medicine strategy: $2014-2023$ https://www.who.int/publications/i/ite $\mathrm{m} / 9789241506096$

WHO $\left(2020^{2}\right)$. World Health Organization. Director-General's opening remarks at the media briefing on COVID-19 - March 11th 2020 (Accessed 15 ${ }^{\text {th }}$ September 2020), https://www.who.int/dg/ speeches/detail/who-director-general-sopeningremarks-at-the-media-briefingon-covid-19-11-march-2020.

WHO $\left(2020^{\mathrm{b}}\right)$ World Health Organization. Coronavirus symptoms. https://www.who.int/healthtopics/coronavirus\#tab=tab_3 Accessed $20^{\text {th }}$ October, 2020.

WHO $\left(2021^{2}\right)$. World Health Organization. WHO Coronavirus (COVID-19) Dashboard | WHO Coronavirus Disease (COVID-19) Dashboard. Accessed 22 ${ }^{\text {nd }}$ March, 2021.

WHO $\left(2021^{\mathrm{b}}\right)$. World Health Organization. 
Coronavirus disease (COVID-19): Vaccines (who.int). Accessed $22^{\text {nd }}$ March, 2021.

Willcox, M.L. and Bodeker, G., 2004. Traditional herbal medicines for malaria. Bmj, 329(7475), pp.1156-1159.

Wu, C., Liu, Y., Yang, Y., Zhang, P., Zhong, W., Wang, Y., Wang, Q., Xu, Y., Li, M., Li, X. and Zheng, M., 2020. Analysis of therapeutic targets for SARS-CoV-2 and discovery of potential drugs by computational methods. Acta Pharmaceutica Sinica B. https://doi.org/10.1016/j.apsb.2020.02. 008.

Wu, C.C., Ko, F.N., Wu, T.S. and Teng, C.M., 1994. Antiplatelet effects of clausine-D isolated from Clausena excavata. Biochimica et Biophysica Acta (BBA)-General Subjects, 1201(1), pp.1-6.

Xu, X., Zhang, Y., Li, X. and Li, X.X., 2020. Analysis on prevention plan of corona virus disease-19 (COVID-19) by traditional Chinese medicine in various regions. Chin. Tradit. Herb. Drugs, 51, pp.18.

Yahya, A., Wnawa, W. and Abdullah, N.A., 2018. In vitro immuno-modulatory activity of aqueous Quercus infectoria gall extract. Asian J Med Biomed, 2(S1), p.30.

Yang, H.K., Jung, M.H., Avunje, S., Nikapitiya, C., Kang, S.Y., Ryu, Y.B., Lee, W.S. and Jung, S.J., 2018. Efficacy of algal Ecklonia cava extract against viral hemorrhagic septicemia virus (VHSV). Fish \& Shellfish Immunology, 72, pp.273-281.

Yang, L., Cui, X.Y. and Zhang, H., 2007. A n t i infla m matory and immunomodulation effects of the extract of Scutellariabaicalensis Georgi. Chin Pharm, 18, pp.1856-7.

Yang, X.L., Liu, D., Bian, K. and Zhang, D.D., 2013. Study on in vitro anti-inflammatory activity of total flavonoids from Glycyrrhizae Radix et Rhizoma and its ingredients. Zhongguo Zhong yao za zhi= Zhongguo zhongyao zazhi= China journal of Chinese materia medica, 38(1), p.99.

Yang, Y., Islam, M.S., Wang, J., Li, Y. and Chen, X., 2020. Traditional Chinese medicine in the treatment of patients infected with 2019- new coronavirus (SARS-CoV-2): a review and perspective. International journal of biological sciences, 16(10), p.1708.

Ye, X.Y., Ng, T.B., Tsang, P.W. and Wang, J., 2001. Isolation of a homodimeric lectin with antifungal and antiviral activities from red kidney bean (Phaseolus vulgaris) seeds. Journal of protein chemistry, 20(5), pp.367375.

Yin, Y. and Wunderink, R.G., 2018. MERS, SARS and other coronaviruses as causes of pneumonia. Respirology, 23(2), pp.130-137.

Yoshimoto, F.K., 2020. The Proteins of Severe Acute Respiratory Syndrome Coronavirus-2 (SARS CoV-2 or $\mathrm{n}$ COV19), the Cause of COVID-19. The Protein Journal, p.1.

Zagórska-Dziok, M., Ziemlewska, A., NiziołLukaszewska, Z. and Bujak, T., 2020. Antioxidant Activity and Cytotoxicity of Medicago sativa L. Seeds and Herb Extract on Skin Cells. BioResearch Open Access, 9(1), pp.229-242.

Zhang, W., Du, R.H., Li, B., Zheng, X.S., Yang, X.L., Hu, B., Wang, Y.Y., Xiao, G.F., Yan, B., Shi, Z.L. and Zhou, P., 2020. Molecular and serological investigation of 2019$\mathrm{nCoV}$ infected patients: implication of multiple shedding routes. Emerging microbes \&infections, 9(1), pp.386-389.

Zhang, B.L, Liang S.R, Zhang, J.P, 2004. Syndrome in TCM and Therapeutic Effect of Integrated Medicine in Patients with SARS. Tianjin Journal of Traditional Chinese Medicine 21:462-466. (Chinese)

Zhang, B.L. Liang, S.R. Zhang, J.P. Wang, H.W.. Ma, R. Sun, Z.T Gao, X.M. Jia, Y.T. Zhang, H.L. and Zhu, Y.X. 2020. One highly suspected case of novel coronavirus pneumonia treated by Integrated Traditional Chinese and Western medicine and nucleic acid analysis. Tianjin Journal of Traditional Chinese Medicine. 0227, p.004.

Zhang, J., Yamada, S., Ogihara, E., Kurita, M., Banno, N., Qu, W., Feng, F. and Akihisa, T., 2016. Biological activities of triterpenoids and phenolic compounds from Myrica cerifera bark. Chemistry \& biodiversity, 13(11), pp.1601-1609.

Zhang, L., Koyyalamudi, S.R., Jeong, S.C., Reddy, 
N., Bailey, T. and Longvah, T., 2013. Immunomodulatory activities of polysaccharides isolated from Taxillus chinensis and Uncaria rhyncophylla. Carbohydrate polymers, 98(2), pp.1458-1465.

Zhang, Q., Xu, Y., Lv, J., Cheng, M., Wu, Y., Cao, K., Zhang, X., Mou, X. and Fan, Q., 2018. Structure characterization of two functional polysaccharides from Polygonum multiflorum and its immunomodulatory. International journal of biological macromolecules, 113, pp.195-204.

Zhang, W., Tao, J., Yang, X., Yang, Z., Zhang, L., Liu, H., Wu, K. and Wu, J., 2014. Antiviral effects of two Ganoderma lucidum triterpenoids against enterovirus 71 infection. Biochemical and biophysical research communications, 449(3), pp.307-312.

Zhao, G.R., Xiang, Z.J., Ye, T.X., Yuan, Y.J. and Guo, Z.X., 2006. Antioxidant activities of Salvia miltiorrhiza and Panax notoginseng. Food chemistry, 99(4), pp.767774.

Zhao, Z., Xiao, J., Wang, J., Dong, W., Peng, Z. and An, D., 2015. Anti-inflammatory effects of novel sinomenine derivatives.
International Immunopharmacology, 29(2), pp.354-360.

Zhao Y, Zhao Z, Wang Y, Zhou Y, Ma Y, Zuo W 2020. Single-Cell RNA Expression Profiling of ACE2, the Receptor of SARS-CoV-2. American Journal of Respiratory and Critical Care Medicine, 202(5) pp. 756-759.

Zheng, L.J., Luo, Y.P., Wang, Y.J., Xing-Guo, H.U., Zhi-Qing, W.U. and Bao, F.K., 2011. Advances in the study of the antibacterial and anti-inflammatory action of Galla chinensis. Journal of Pathogen Biology, 6(11), pp.868-1105.

Zhong, T., Zhang, L.Y., Wang, Z.Y., Wang, Y., Song, F.M., Zhang, Y.H. and Yu, J.H., 2017. Rheum emodin inhibits enterovirus 71 viral replication and affects the host cell cycle environment. Acta Pharmacologica Sinica, 38(3), pp.392-401.

Zubair, M., Widén, C., Renvert, S. and Rumpunen, K., 2019. Water and ethanol extracts of Plantago major leaves show antiinflammatory activity on oral epithelial cells. Journal of traditional and complementary medicine, 9(3), pp.169-171. 